LEILA STRAZZA

\title{
DIFERENÇAS DE GÊNERO E RISCO PARA A INFECÇÃO PELO HIV EM ADOLESCENTES INTERNOS DA FUNDAÇÃO ESTADUAL PARA O BEM-ESTAR DO MENOR DE SÃO PAULO FEBEM
}

Dissertação apresentada à Faculdade de Medicina da Universidade de São Paulo para obtenção do título de Mestre em Ciências

Área de Concentração: Fisiopatologia Experimental Orientador: Prof. Dr. Eduardo Massad

SÃO PAULO

1999 


\section{INTRODUÇÃO}

A síndrome da imunodeficiência adquirida (AIDS) não é um problema puramente médico, pois traz consigo muitas questões ligadas à cultura que devem, não apenas serem respeitadas, como também, avaliadas e trabalhadas na sua essência: a cidadania, a sexualidade, o medo, os preconceitos, o gênero, a política social e econômica de cada país (estado, região).

A cidadania é um ponto central para o profissional que se propõem a trabalhar com esta doença. O que é ser um cidadão? Poder usufruir direitos como a educação e a saúde, e cumprir obrigações para com a sociedade, permitindo que outros possam ser também cidadãos.

Nota-se que a AIDS, geralmente, retira o indivíduo do contato social quando ele atinge um precário estado de saúde e, ainda, faz gerar no outro, algumas vezes, o medo e o preconceito diante de uma doença incurável. O que lhe resta então para agir como cidadão?

Como fica a política social e econômica de um país subdesenvolvido? Será capaz de dar proteção ao cidadão?

Não. Basta lembrar-se da cultura Patriarcal e Machista, que é, facilmente, demonstrada através das relações de gênero e suas respectivas sexualidades, ou seja, ser homem, implica em ser "machão" e ser mulher é sinônimo de ser "submissa".

Onde existe um “não saber”sobre AIDS que não está ligado com o nível sócioeconômico, escolaridade, mas sim a atitudes transmitidas através desta cultura onde o homem tem uma relação de poder com o contrôle quase absoluto da relação sexual e que a maioria das mulheres confrontam-se com a questão da infidelidade, como se o relacionamento sexual com o marido fosse uma armadilha em que falar sobre camisinha com o marido é "FEIO", é admitir a presença da "OUTRA" como figura existente, que só existe para "DESTRUIR”a família (Patriarcal)! Porém, não falar sobre a camisinha "dá medo de pegar doença ruim...”(PAIVA,1992). 
A mudança de comportamento no Brasil, como em todos os países do mundo(LEARY e CHENEY, 1993), vem mostrar a urgente necessidade de uma reflexão profunda sobre as relações entre o gênero masculino e feminino.

Incorporar o uso da camisinha seria o início de uma grande transformação, ou melhor, o consenso entre gêneros, que se iniciaria com homens e mulheres negociando o uso da camisinha e experimentando práticas sexuais tão contrárias às atitudes de anos, mas que não são impossíveis de serem assumidas(PAIVA, 1992).

Sem trabalhar esta questão, fundamental, é impossível pensar em sexo seguro diante da epidemia deste século.

Tome-se então os adolescentes, uma geração nascida durante a deflagração da epidemia, e criada com o conhecimento oferecido pelos projetos de Saúde, aulas na escola, e todo arsenal da mídia: como ficam suas atitudes, práticas, posturas e hábitos no cotidiano? Serão capazes de colocarem em prática tamanho volume de conhecimentos e informações recebidas e praticarem o sexo seguro? Será que este conhecimento disponibilizado há quase duas décadas lhes torna invulneráveis ao vírus HIV?

E o que dizer daquela adolescência que se contrapõe à ordem estabelecida e se coloca à margem da sociedade? Que complexidades se somam ao comportamento de adolescentes infratores impondo-lhes mais um risco - contrair o vírus da AIDS? 


\subsection{Epidemiologia da AIDS}

A caracterização da síndrome da imunodeficiência adquirida (AIDS) como doença começou a partir de casos de pneumonia por Pneumocystis carinii e sarcoma de Kaposi em homossexuais masculinos no final da década de 70. Ambas doenças raramente eram observadas entre pessoas jovens e foram associadas à uma imunodeficiência de origem não esclarecida.

Com a descoberta do vírus da imunodeficiência humana (HIV) como agente etiológico da AIDS, tornou-se possível a partir de 1981 caracterizar a epidemiologia desta pandemia (EVANS, 1989).

A casuística teve um rápido crescimento e levou a uma intensa mobilização dada a gravidade da doença. (HUMINER, 1987).

Como o estudo da incidência, inicialmente, estava mais voltado para os homossexuais masculinos, procurava-se uma ligação entre a homossexualidade e a AIDS na clínica, na opinião pública, no julgamento moral, nas pesquisas, nos comportamentos específicos ou canais transmissores capazes de justificarem tal incidência e poder criar-se esquemas de prevenção e terapêutica.

Um caso ilustrativo desta tentativa é o do comissário de bordo Gaetan Dugas, “o anjo da morte”. Conta-se que ele conheceu um jovem africano em Paris em 1977 com quem teve relações sexuais. Morreu em 1984 com uma espantosa devastação contabilizada, pois dos primeiros 248 casos de AIDS registrados nos Estados Unidos, pelo menos 40 estavam relacionados a ele (BUCHALLA, 1993).

No entanto, demonstrou-se que a transmissão do HIV se dava também por outras vias, além da sexual (homo e heterosexual): via parenteral e transplacentária.

$\mathrm{Na}$ África a epidemia de AIDS é muito prevalente, sendo que a transmissão do vírus nas relações heterosexuais é particularmente preponderante em áreas urbanas. A introdução do vírus nestas áreas se deveu principalmente pelo contato com a população de prostitutas (EVANS, 1989).

A epidemia da AIDS na América Latina e Caribe reflete a heterogenoidade da epidemia do HIV no mundo, porém difere de país para país e, também, dentro de cada 
país. Na maioria dos casos, o vírus HIV concentra-se em populações que vivem à margem da sociedade. Tem maior incidência em homens que fazem sexo com outros homens e usuários de drogas injetáveis.

No contexto global, estima-se que 30,6 milhões de pessoas estejam vivendo com o vírus HIV, incluindo-se 1,1 milhão de crianças menores de 15 anos de idade. A tendência é para mais de 60 milhões de pessoas estarem infectadas com este vírus no ano 2.000. Mais de 90\% destas pessoas moram na Ásia, Africa, América Latina e Caribe (MINISTÉRIO DA SAÚDE,1999).

A relação de casos entre o gênero masculino e feminino tem diminuído no Estado de São Paulo, conforme mostram os coeficientes de incidência/100.000 habitantes (Figura 1), segundo dados da Secretaria de Estado da Saúde (BOLETIM EPIDEMIOLÓGICO, 1999). Dos 79.761 casos notificados desde o princípio da epidemia em 1980 até o mês de abril de 1999, 61.055 (76,5\% ) são homens, e 18.708 $(23,5 \%)$ mulheres; a taxa de letalidade acumulada até esta data é de $61,5 \%$, ou seja 49.055 pessoas morreram de AIDS no Estado de São Paulo a partir de 1980. As categorias de transmissão do vírus para o sexo masculino, em ordem decrescente são: usuários de drogas injetáveis (29,8\%), relações homossexuais (20,4\%), relações heterossexuais $(18,9 \%)$, relações bissexuais $(8,5 \%)$, hemofílicos $(0,6 \%)$ e transfusões de sangue $(0,6 \%)$. Em 5,9\% dos casos a via de transmissão pode ter sido tanto sexual (homens que fazem sexo com homens) quanto por uso de droga injetável, constitundo assim uma categoria a parte; os restantes $15,4 \%$ ainda não tem via de transmissão definida, estando sob investigação. Para o sexo feminino o perfil de transmissão é

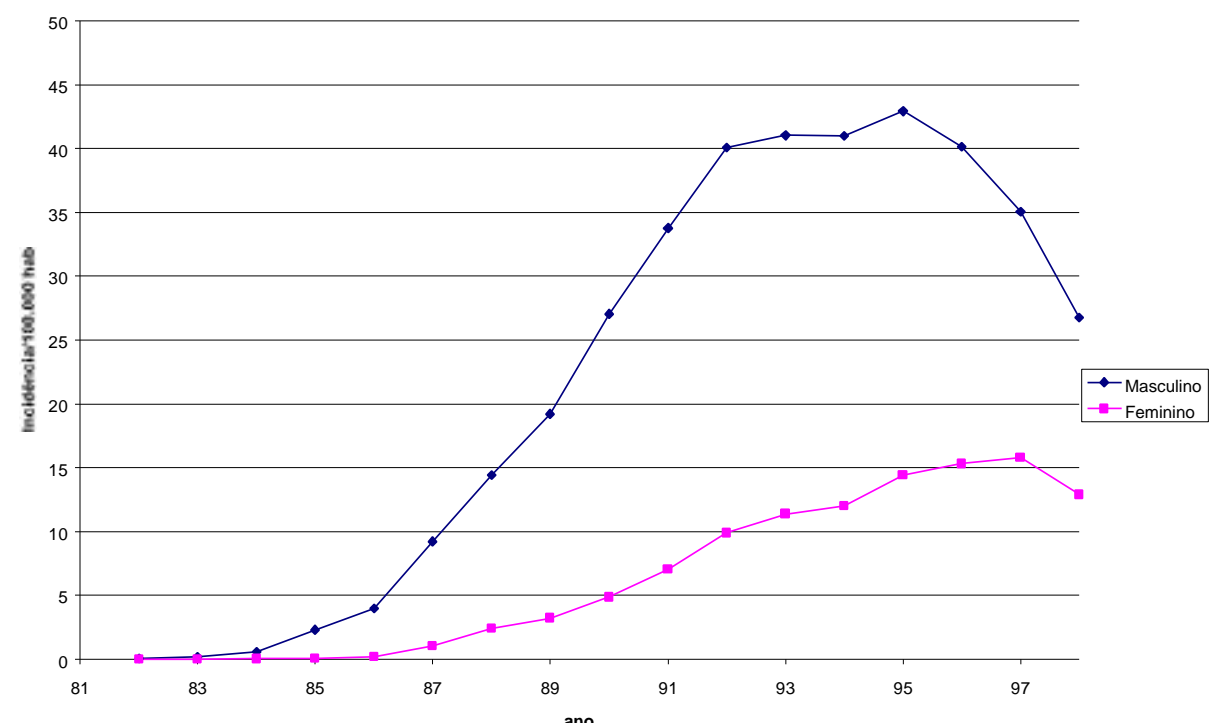

Figura 1 - Coeficiente de incidência/100.000 habitantes/ano de casos de AIDS no Estado de São Paulo (modificado de BOLETIM EPIDEMIOLÓGICO, 1999) 
diferente, a saber: relação heterossexual (62,1\%), uso de droga injetável $(23,2 \%)$, transfusão de sangue (1,5\%), restando 13,3\% dos casos sem definição, sob investigação.

A faixa etária com maior número de casos está entre 20 e 39 anos de idade (57.879 casos); em segundo lugar pessoas entre 40 e 59 anos (15.825 casos); e em terceiro lugar crianças e jovens do nascimento aos19 anos de idade (4.461 casos). Pessoas com mais de 60 anos representam 1275 casos. Deve ser destacado que os casos em crianças com menos de 1 ano somam 1.138 notificações desde 1980, e que 1.796 casos são de adolescentes entre 15 e 19 anos (BOLETIM EPIDEMIOLÓGICO, 1999).

Estes dados globais apontam importantes diferenças epidemiológicas quanto ao gênero e idade, evidenciando a necessidade de se compreender os comportamentos de risco que envolvem a transmissão do HIV de modo estratificado. 


\subsection{Contribuições da psicanálise para compreensão da personalidade infratora na adolescência.}

Muitos fatores podem contribuir para que adolescentes passem a ter um comportamento anti-social, tornando-se delinquentes. A própria adolescência é tida como época complexa da vida de uma pessoa, quando situações positivas e negativas convivem intensamente.

Para ABERASTURY e KNOBEL (1981) o adolescente tem, como objetivo central de sua vida, buscar a sua própria identidade, sendo que nesta busca passa obrigatoriamente por três lutos:

luto pelo corpo infantil: a mudança física é algo externo e a pessoa a assiste como expectador. Acontece como uma base biológica da adolescência;

- luto pelo papel e a identidade infantil: renúncia de dependência e aceitação de responsabilidades;

luto pelos pais de infância: tentativa de reter na personalidade do adolescente o refúgio e a proteção da personalidade dos pais.

Esses lutos levam os adolescentes à instabilidade. Os pais, neste momento, podem estar enfrentando esse difícil momento de seus filhos com algumas características inerentes ao envelhecimento, que pode vir a dificultar a comunicação com seus filhos.

Esse luto vem acompanhado, segundo ABERASTURY e KNOBEL (1981), por um processo dinâmico do luto normal com fases transitórias que acabam por adquirir características de luto patológico, em virtude da crise essencial da adolescência que sofre os impactos de uma realidade que se torna muito frustante.

O adolescente apresenta uma vulnerabilidade capaz de assimilar os impactos projetivos de pais, irmãos, sociedade...ou seja, é como se fosse um receptáculo que se encarrega dos conflitos seus e alheios, principalmente, os doentios do meio em que vive. 
Com essa afirmação nos remeteremos à uma comparação com a sociedade, que projeta suas falhas nos chamados EXCESSOS DE JUVENTUDE e que os(as) responsabiliza pela delinquência, drogas, prostituição...

É esta sociedade que recorre ao mecanismo esquizóide de KLEIN (1973) em que bastante cedo faz com que o ego tenha uma relação com 2 objetos: seio bom (ideal) e seio mau ( persecutório ) - ( split ).

-Seio bom (ideal ) - experiências gratificantes de amor e alimentação recebidas pela mãe que se tornam algo protetor;

- Seio mau ( persecutório ) - fantasia de perseguição, funde-se com experiências reais de privação e sofrimento, partes do eu que contêm o instinto de morte.

Várias partes do eu ( self ) podem ser projetadas com vários objetivos:

- partes más do eu podem ser projetadas a fim de livrarem-se delas, para atacar e destruir o objeto ( a mãe);

- partes boas podem ser projetadas para evitar separação ou para mantê-lo a salvo dos objetos maus internos.

Devemos olhar os mecanismos de defesa usados na posição esquizo-paranóide não apenas como mecanismos de defesa que protegem o ego de ansiedades imediatas e esmagadoras, mas sim como etapas necessárias ao desenvolvimento do indivíduo.

A relação com o seio bom contém um certo grau de idealização que o conduz ao apaixonar-se, apreciar a beleza, formar ideais sociais e políticos.

A relação com o seio mau o conduz à falta de descriminação entre bom e mau e a fixação em objetos maus.

Nesta posição esquizo-paranóide é essencial que as experiências boas prevaleçam sobre as más para que o ego adquira crença na prevalência do objeto ideal sobre os objetos persecutórios, bem como, no seu próprio instinto de vida sobre seu próprio instinto de morte. 
WINNICOTT (1982) enriquece a psicanálise com sua forma de discutir a delinquência como uma defesa anti-social organizada que é sobrecarregada com ganho secundário e reações sociais.

Esta tendência pode ser encontrada em todas as idades no individuo, denominado normal, ou num psicótico ou neurótico.

Esclarecendo sobre a tendência anti-social de WINNICOTT (1982), que diz que existe um complexo de privação que ocorre quando uma criança sofre de privação, ou seja, quando lhe faltam certas características que lhe são essenciais da vida familiar, que o (a) faz expor um comportamento anti-social. Em virtude desta tendência , a pessoa será considerada como desajustada ou levada ao tribunal como incontrolável. Porém, na delinquência a criança pode ser mandada para um reformatório.

A repetição de crimes é denominado como reincidência .

A tendência anti-social implica na esperança, na compreensão do ato. É, fundamental, no tratamento, o momento ato anti-social, ele não deve ser desperdiçado.

Existe a relação direta entre a tendência anti-social e a privação, a qual BOWLBY (1982) é o grande precursor e abriu portas para especialistas desta área.

Segundo WINNICOTT (1982), quando existe esta tendência anti-social há um desapossamento (não é uma carência ), uma perda de algo bom, positivo na experiência da pessoa até aquela data em que foi retirado. Essa retirada foi por um período maior do que se pode manter viva a lembrança da experiência boa. A privação inclui o ponto exato do trauma sofrido e a persistência da condição traumática.

Numa explicação mais detalhada vamos nos referir a posição depressiva de KLEIN (1975 ) que foi construída sob o entendimento da melancolia de FREUD (1974). KLEIN (1975 ) deu importância a morte do objeto interno através da raiva e do contato de objetos bons junto aos produtos de ódio no interior da psique ou a imaturidade do ego capaz de afetar a capacidade de manter viva uma lembrança.

KLEIN (1975) elaborando esse impulso destrutivo do mundo, interior do indivíduo, converte-o no desejo de reparar, construir, assumir a responsabilidade. 
Queremos esclarecer que posição é diferente de fase:

- posição - depende do momento que o indivíduo está vivendo, ela se alterna a vida toda;

- fase é a fase oral do Freud, por exemplo.

Voltando à delinquência como um ato anti-social (WINNICOTT, 1995) que pode levar ao crime, diremos que a atitude sentimentalista em relação ao crime leva ao ódio recalcado e esse recalcamento não é saudável. Lembremos que o crime produz sentimentos de vingança pública, que redundaria em algo perigoso, sendo que o mesmo, é afastado num tribunal por um magistrado que, não apenas, estabelece a sentença, como também, a chance de um tratamento humano ao infrator, que é uma pessoa doente .Dito isto WINNICOTT (1995), torna-se, mais claro, ao afirmar que o criminoso retém uma doença psicológica que deve ser tratada, pois é apresentada como recuperável.

Numa família onde marido e mulher assumem a responsabilidade de uma criança, somos cientes de que os estágios iniciais do desenvolvimento emocional são conflitantes e repletos de desintegrações potenciais, o qual torna a criança um ser destrutivo, mas o lar o (a) ajudará a suportar toda esta desorganização e faz com que ele(a) vá brincar, saudavelmente (WINNICOTT, 1975).

Na delinquência desenvolvida, a situação fica difícil, neste momento, pois a criança busca um protetor para recuperar seus impulsos primitivos de amor, o seu desejo de recuperar-se...mas, ela está só, o que por conseguinte, fará com que cada vez fique mais deprimida e despersonalizada, incapaz de sentir a realidade das coisas, exceto a realidade da violência...claro! Só lhe resta o ato anti-social que, nada mais é, do que um S.O.S. pedindo o controle de pessoas fortes, amorosas e confiantes (WINNICOTT, 1995). 


\title{
1.3. - O Adolescente e a Sociedade
}

\author{
"É muito difícil assinalar o limite entre o normal e o patológico na \\ adolescência”.
}

( FREUD, 1958)

Somos cientes da importância dos pais em relação aos filhos na determinação de seu caráter, na personalidade em desenvolvimento, do nascimento à idade escolar, onde deve estruturar-se o futuro do indivíduo. Nesse período estabelece-se o modo como o indivíduo relaciona-se com os outros, de acôrdo com a herança de si mesmo trazida da infância, que quando privada ou carente de amor, pode desenvolver pelo seu próximo completa indiferença, desamor ou mesmo ódio. Uma incapacidade de se dar ao outro, porém uma exigência total de todos (DOURADO, 1969). Assim será facilitada a mentalidade pré-criminal que se distinguirá pela temida imagem criada, que antes de ser "idealizada”, já é uma imagem estática, que ao invés de humilde será arrogante, mas que será muito valorizada, em seu meio, quanto mais a pessoa apresentar o seu lado machista em progressão e não o seu lado feminino, cujo modêlo será:

- bruto(a), valente, temido(a) pelos outros.... sanguinário(a) (DOURADO, 1969).

Exempliflicando o acima (DOURADO, 1969) com o ladrão de automóvel, podemos dizer que só pelo fato de sê-lo, sente-se forte, onipotente pelo próprio ato que o compensa de suas carências afetivas e faz com que o carro roubado lhe facilite a companhia de uma mulher, que ele não amará, naturalmente, mas sim, a violentará através de seu machismo

Segundo PELLEGRINO (1983) não podemos nos esquecer que o pai é o primeiro e, fundalmentalmente, representante junto à criança, da Lei da Cultura. Se ocorre uma ruptura fica destruído o significante paterno e em consequência o lugar da 
Lei. Tudo o que ficou reprimido com o pacto e com o pai, vem à tona sob forma de conduta delinquente e anti-social.

A personalidade se constrói e torna-se diferenciada através de uma série de identificações "processo psicológico pelo qual uma pessoa assimila um aspecto, uma propriedade, um atributo de outra e transforma-se total ou parcialmente a partir desse modêlo" (LAPLANCHE \& PONTALIS, 1967 ) É muito difícil para o adolescente inserir-se neste mundo (MARTINS, 1997) e para o(a) infrator(a) que, já, soma um deficit afetivo inicial e que continua o seu caminho sem a orientação de um modêlo, tudo fica, ainda, mais difícil, pois ele(a) não consegue enfrentar os seus problemas e os mascara com um falso destemor, protegido por um líder de grupo, um "führer" (REICH, 1988), que significará a transferência do pai tão ausente e/ou desejado (CORNEAU, 1991; MARTINS, 1997).

Ter um líder brilhante no grupo o(a) reduzirá a mais insignificante e cega submissão do mundo do(a) infrator(a), que para esta população chamaremos como o início de uma quadrilha.

Sendo pleonásticos quanto ao grupo e colocando-o dentro da sociedade em que vivemos com um quadro de diferenças sociais e econômica, sabemos que ela acaba por conduzir à violência e destruição e que ela não oferece garantias suficientes de sobrevivência a estes(as) jovens, obrigando-os(as) a um comportamento defensivo, a ir em busca de ideais e de figuras ideais para maior identificação ( SOUZA, 1986; MARTINS, 1997).

É, exatamente, com esta combinação de armas, gangues, drogas, pobreza e jovens atemorizados e sem esperança que tivemos a morte de cerca de 50.000 jovens, desde 1979; o equivalente ao total de mortes em combate na guerra do Vietnã (STRAUS, 1994). Pesquisas feitas, recentemente (DRYFOOS, 1990) mostram que um em cada quatro adolescentes corre o sério risco de tornar-se um adulto irresponsável, pois os(as) mesmos(as) não estão adquirindo habilidades, suficientes e necessárias, à participação do sistema educacional e o cumprimento à força de trabalho. A vida familiar desses jovens é limitada, tornando-os incapazes de serem pais responsáveis. 
Resumindo, a pesquisa DRYFOOS (1990) afirma que uma nova classe está surgindo :

- “ os intocáveis” - são pessoas analfabetas desligadas da escola, deprimidos(as), propensos(as) ao uso excessivo de drogas, pais de filhos indesejados, e, infelizmente, terminam a ligar-se à vida criminal.

GRINBERG (1961) alerta sobre o sentimento antecipatório de ansiedade e depressão do ego que jovens passam, obrigando-os a agarrar-se a um precário estado de identidade. Destaca a possibilidade da desconformidade da personalidade adquirida e o desejo de conseguir outra através da identificação projetiva. Ressalta as primeiras etapas do desenvolvimento de um bebê que pode invejar o peito que não o satisfaz e fantasia de sua destruição, de acôrdo com a teoria de KLEIN (1973).

Quem é a sociedade, neste momento, para esta população?

Uma condição externa vivida por esses(as) adolescentes que tem influência no processo ideológico vivido por eles(as) (SOUZA, 1986) e um ideal, que segundo COSTA (1994), antes era baseado na virtude, porém, hoje, o que vale mesmo, é o sucesso sem interessar-se pelos meios de se chegar a ele.

Vale lembrar, também, que o desêspero tem como uma das causas a violência que ao compararmos com a institucionalizada, a qual todos nós estamos submetidos, a frequência da violência direta dos infratores, nos faz chegar a conclusão que ela se torna mínima! A violência institucionalizada não é percebida e combatida como violência, visto que não implica, necessariamente, em ato agressivo (SOUZA, 1986) e combatê-la significa alterar a própria estrutura social.

Não vamos nos referir a violência como um impedimento de exercer os direitos de cidadão, direito à vida e liberdade, à segurança, educação e saúde, mas sim, aos furtos e crimes comuns cometidos pelo "Zé povinho" que viola os direitos dos cidadões, ou seja, aqueles que as classes dominadas estão submetidas (SOUZA, 1986).

A sociedade em que vivemos, faz com que o(a) adolescente que está tentando planejar sua vida, controlar suas mudanças, adaptar-se ao mundo e suas necessidades 
imperiosas, sugue o seio mal de KLEIN (1975), entre no seu conflito pessoal, deparese com as frustrações diárias do cotidiano. Esta, talvez, seja a forma de explicar os seus desejos e necessidades de reformas sociais. Reprimir um jovem com severidade e violência acaba criando um distanciamento maior e um agravamento de conflito, que colabora para sua agressão social.

OLIVEN (1983) enfatiza que as grandes cidades, centros mais dinâmicos do capitalismo no Brasil, são o espaço onde a riqueza e a opulência confronta-se com a maior miséria, ficando claro o porquê das maiores formas de violência.

O problema da adolescência deve ser visto como um processo universal de troca, de desprendimento que é , altamente, influenciado pelo mundo externo que varia de acôrdo com a cultura de cada país (estado, cidade, bairro) que gerarará facilidades ou dificuldades peculiares.

PELLEGRINO (1983) diz que o surto de delinquência que, no momento, cresce nas grandes cidades, de maneira assustadora, é, apenas, uma resposta ao capitalismo selvagem brasileiro, ou seja, uma resposta dos fora da lei contra a lei, que torna-se pior do que a deliquência institucionalizada das classes dominantes.

PELLEGRINO (1983) não considera a deliquência das massas uma resposta adequada a delinquência do capitalismo brasileiro, mas sim, coloca como condição obrigatória essas massas se organizarem e se politizarem para serem capazes de transformar a sociedade (VÁZQUEZ, 1990). E FREIRE (1991) lembra que a leitura crítica da realidade se constitui como um instrumento necessário de resgate à cidadania do indíviduo que luta nos movimentos sociais, não apenas, pela melhoria da qualidade de vida, mas também, pela transformação social.

Para FRIGINI (1997) “O ser humano não pode ser considerado de forma isolada, mas sempre dentro de um contexto mais dilargado, isto é, no cerne de um complexo numeroso visualizado pela sociedade, pois é parte desse todo".

Queremos dizer, antes de fecharmos as nossas considerações sobre a Adolescência e Sociedade, que muitos destes infratores(as) entrevistados(as) por nós, tiveram genitores desconhecidos, foram criados pela caridade do outro e impelidos, muito cedo, para a sarjeta, sendo que outros permaneceram sob o mesmo teto de ódio 
permanente entre seus pais; assistiram à cenas de alcoólatras, imitaram pais criminosos, sofreram castigos físicos (ZHANG, 1996; BOOTH,1996; SIBTHORPE,1995; BOOTH \& KOSA, 1993; FEITEL,1992; FARROW, 1991; DEISHER, 1991) expuseram seus corpos a maior miséria social e abandono econômico que termina por conduzi-los à criminalidade citada e é claro, a AIDS! (STRAZZA, 1997; EISENSTEIN, 1993; ECKERSLEY, 1993; RESNICK,1993; ENGLISH,1991; DEISHER \& ROGERS, 1991; FARROW, 1991).

Quanto a esta herança, a que estamos nos referindo, (DE GREEFF, 1969) acreditamos na predisposição geral da transmissão desenvolvida com a influência do meio vivido pelo indivíduo, assim como uma pessoa subnutrida (FRANK \& ZEISEL,1998) está mais predisposta a contrair tuberculose pulmonar, ou seja, predisposta e não, necessariamente, obrigada. 


\section{4 - Comentários sobre adolescentes infratores no Brasil e no mundo}

Em 1989 o Brasil contava com uma população de 59 milhões entre crianças e adolescentes, representando um total de $41 \%$ da população.

Neste ano acima citado, 50,5\% fazia parte de famílias cujo rendimento mensal era de 1/2 salário mínimo e 27,4\% recebiam $1 / 4$ (ou menos) de um salário mínimo; 55\% vivia sem esgoto, $43 \%$ sem água encanada, $46 \%$ sem coleta de lixo e $18 \%$ sem luz elétrica ( VOLPI, 1997).

A violência agravou-se nas duas últimas décadas no Brasil e na América Latina, em geral, como consequência da política ecônomica que condenou milhões de pessoas à pobreza e exclusão social. Os mais afetados pelo desemprego e carentes do ensino público foram os que sofreram (e sofrem) maior risco de tornarem-se vítimas da violência da polícia e da criminalidade (VOLPI, 1997).

Em 1994/95 essa comunidade de meninos(as) representava um total de 4.250 crianças e adolescentes, transgressores da lei, que representava uma prevalência de 2,7/100.000 habitantes. A maioria deles(as) são de áreas metropolitanas, sendo que, $36 \%$ vem de cidades do interior de São Paulo (ZANETTA et al., 1999).

Estes adolescentes são predominantemente do sexo masculino (95\%) com uma formação cultural incompleta (97\%) e considere-se ainda o índice de analfabetos (15\%) (ZANETTA et al., 1999).

Aqui vamos lembrar FREIRE (1991; FREIRE, 1979) ao questionar sobre a educação. Será que saber assinar o nome significa ser alfabetizado?

Quanto às drogas ílicitas podemos dizer que 53\% deles(as) as usam na capital, sendo que no interior de São Paulo é significativamente mais baixa esta porcentagem.

Com respeito à seus delitos: $33 \%$ roubos, $24 \%$ assaltos e $18 \%$ assassinatos (ZANETTA et al., 1999).

Em 13 de julho de 1990 foi sancionada, pelo Presidente da República, a Lei ${ }^{\circ}$ 8.069, que dispõe sobre o Estatuto da Criança e do Adolescente (ECA). Considera-se 
criança a pessoa até doze anos incompletos, e adolescente, entre 12 e 18 anos de idade (FERREIRA, 1999).

Às crianças que cometem atos infracionais são aplicadas as medidas de proteção, previstas no artigo 101 (artigo 105).

Para os adolescentes, autores de ato infracional, a autoridade competente poderá aplicar as seguintes medidas (artigo 112):

I - advertência;

II - obrigação de reparar o dano;

III - prestação de serviços à comunidade;

IV - liberdade assistida;

V - inserção em regime de semiliberdade;

VI - internação em estabelecimento educacional;

VII - qualquer uma das previstas no artigo 101, I a VI.

Em São Paulo no Governo de 1995 estabeleceu uma política estadual de defesa dos direitos da criança e do adolescente com uma gestão descentralizada e moderna, otimizando os recursos existentes. A política atendimento às crianças e adolescentes, segundo este governo, fez com que se estabelesesse a concretização através de:

- política social (saúde, educação, cultura, esporte, lazer, habitação e trabalho);

- política de assistência social (para quem necessitar);

- política de proteção especial, destinada à crianças e adolescentes em situação de risco pessoal e social: vítimas de abandono e tráfico; trabalho abusivo e explorador; abuso; negligência e maltrato; que moram ou lutam pela vida nas ruas; que são prostituídos; que estão em conflito com a lei em razão do cometimento de ato infracional (FERREIRA, 1999). 
Para o atendimento destes adolescentes, em conflito com a lei, a Fundação para o Bem-Estar do Menor de São Paulo (FEBEM) possui (abril/1998):

- 94 unidades (48 postos e sub-postos para liberdade assistida, 7 núcleos para semiliberdade, 25 unidades de internação, 7 unidades de internação provisória, 1 unidade de atendimento inicial, 2 unidades para atendimento de saúde do adolescente internado e 4 escolas-oficinas) (FERREIRA, 1999).

É bom lembrarmos que houve muitas reestruturações na organização da FEBEM que não estamos citando.

Atribuir às crianças e adolescentes infratores(as) a situação sócio-ecônomica de nosso país, parece-nos confortável, mas lembremo-nos que esta, mesma, situação, está variando em seu padrão histórico-cultural, pois estamos vivendo um período em que transparece o quanto a lei está sendo, claramente, violada pelos que estão na sociedade.

Mas a mídia com sua eficiência (e suas falhas), parece que resolveu "bater na porta"dos adolescentes infratores.

A imprensa, com freqüência cada vez maior, tem relatado o envolvimento de adolescentes, no Brasil e no mundo, em atos de violência. Algumas matérias publicadas pelo Jornal da Tarde (JT) em São Paulo demonstram, claramente, como este assunto é tratado (FERREIRA, 1999):

- “11/10/96: relatou-se o aumento de crimes praticados por jovens da classe média alta, observando ainda que a maioria desses jovens seriam usuários de drogas (CRIME..., 1996).

- 21/12/96: menores de 18 anos estariam envolvidos em pelo menos $50 \%$ dos crimes que acontecem na Cidade e, segundo o diretor do Fórum da Infância e da Juventude daquela época, os menores estariam tornando-se cada vez mais violentos (ASSALTANTES..., 1996).

- 22/01/97: divulgou-se que, devido às férias escolares, nos meses de dezembro, janeiro e julho, a criminalidade cresceria até $20 \%$ entre os adolescentes. A justificativa, segundo um juiz, seria que em vez de estarem 
ocupados com a escola, teriam mais tempo livre durante as férias e acabariam se envolvendo com crimes (CAMPOS, 1997).

- 27/06/97: relatou-se os resultados de uma pesquisa divulgada em Nova York, sobre a imagem que os adultos têm dos adolescentes e crianças, cujos adjetivos mais citados foram: irresponsáveis, desrespeitosos, rebeldes, malcriados, mimados; atribuiu-se estes resultados ao reflexo da opinião pública diante de uma sucessão de crimes violentos cometidos por jovens, e a responsabilidade maior por esta crise foi atribuída aos pais e às escolas (JOVENS..., 1997).

- 28/06/97: divulgou-se a preocupação crescente de ministros da área social de 41 países europeus (reunidos em Viena para discutir políticas de apoio aos jovens) com o consumo crescente de bebidas alcoólicas e drogas ilegais. Mais uma vez, os problemas com os adolescentes foram relacionados com uma crise que estaria atingindo a instituição familiar (OS GAROTOS..., 1997).

- 09/08/97: foi a vez do Japão ganhar destaque na imprensa, devido à prisão de um adolescente de 14 anos, acusado de ter decapitado um outro menino, em Kobe. Nesta matéria, divulgou-se que houve um aumento de 59\% no número de adolescentes detidos por crimes violentos no primeiro semestre de 97, em relação ao mesmo período no ano anterior, segundo dados da Agência Nacional de Polícia do Japão. Contando-se qualquer tipo de crime, o número total de adolescentes entre 14 e 19 anos detidos no primeiro semestre de 97 representaria 46,4\% de todas as prisões no país (CRIME..., 1997).

- 03/12/97: divulgou-se que o Congresso norte-americano aprovou em maio/97 uma lei que determina o julgamento de menores a partir de 14 anos, que tenham cometido crimes graves; comenta-se, também, mais um crime cometido nos EUA por um adolescente de 14 anos, que descarregara uma pistola automática contra os colegas no saguão da escola, matando três e ferindo outros seis (D’ALFONSO, 1997). Além destas, publicou-se uma matéria a respeito da violência, considerada uma epidemia nos EUA não apenas entre adolescentes (WASHINGTON POST, 1997). 
- 04/12/97: publicou-se que o governo britânico anunciou projeto de lei para combater a criminalidade infanto-juvenil prevendo, entre outras coisas, o julgamento de crianças com idade a partir de 10 anos, em tribunais de adultos. $\mathrm{O}$ objetivo seria "proteger o público da violência infantil e juvenil, cuja ocorrência se multiplicou nos últimos anos..." (GRÃ-BRETANHA..., 1997).

- 17/01/98: foi divulgada uma pesquisa realizada pela Associação dos Advogados Criminalistas do Estado de São Paulo, em 416 inquéritos policiais, entre maio e novembro de 1997, revelando que 74\% dos crimes cometidos no Estado de São Paulo tiveram participação de menores de idade (GONZALES; TEDESCO, 1998).

Além destas matérias, dois casos estiveram presentes na imprensa durante vários dias: o assassinato do índio patachó, em Brasília, em abril de 1997, que teve a participação de um adolescente junto com outros jovens da classe média e o assassinato de um corretor de imóveis, no Central Park, NY, em maio de 1997, por dois jovens americanos de 15 anos, também de famílias socialmente diferenciadas.

Ao longo de 1998, muitos outros casos de violência envolvendo crianças e adolescentes foram relatados, no Brasil e no mundo(FERREIRA, 1999):

- 25/03/98: Um dia após um tiroteio na porta de uma escola em Arkansas, onde dois garotos (de 11 e 13 anos) mataram 4 alunas e 1 professora, comenta-se a divulgação de uma pesquisa realizada pelo Departamento de Educação dos EUA, realizada em 1.200 escolas públicas nos 50 Estados, mostrando que no ano anterior uma de cada 10 escolas públicas do país foi cenário de episódios violentos (TIROTEIO..., 1998).

- 11/04/98: foi divulgada a prisão de dois adolescentes que confessaram ter matado uma professora, de uma escola de Jacareí, por vingança, pois ela vinha reprimindo o tráfico na escola (PASSARELLI, 1998).

- 16/04/98: o problema do tráfico de drogas, nas escolas de São Paulo, é comentado em uma reportagem sobre um adolescente que invadiu uma escola pública drogado, querendo matar um aluno (SANCHES, 1998). 
- 20/05/98: mais uma vez é abordado o problema das drogas nas escolas, desta vez divulgando-se as experiências dos colégios particulares de São Paulo, com programas de prevenção ao uso de drogas. As escolas assumem que têm dificuldades (TÓFOLI, 1998).

- 23/05/98: divulgou-se que um garoto de 15 anos matou os pais e dirigiu-se à escola, onde descarregou um rifle contra os colegas, matando dois e ferindo outros 22, no Estado do Oregon (EUA). Matéria divulgada relatou que, desde outubro/1997, foram 7 incidentes deste tipo, envolvendo armas de fogo nas escolas americanas (EUA..., 1998).

- 06/06/98: foi divulgado que um adolescente de 17 anos foi condenado à prisão perpétua por assassinato, no primeiro julgamento desde o início da onda de crimes nas escolas que vem abalando os EUA (CRIME..., 1998).

- 15/06/98: uma reportagem comentou o problema da violência nas escolas da zona sul de São Paulo, divulgando também um documento que fora entregue à Secretaria da Segurança Pública: "O tráfico de drogas se instalou dentro dos muros das escolas. Com freqüência cada vez maior, armas são encontradas nas mãos de adolescentes, até com meninas de 13 anos. O clima de terror é tanto que algumas escolas podem ser obrigadas a dispensar os alunos e a fechar as portas." (CAMPOS, 1998c).

E assim continuou em 1999 (FERREIRA,1999):

- Durante vários dias, foram publicadas matérias sobre o massacre ocorrido no dia 20/04/99 em uma escola no Colorado, EUA, quando dois alunos mataram 12 colegas, um professor e suicidaram-se a seguir. Após esta tragédia, muitos outros incidentes ocorreram, envolvendo adolescentes que se inspiraram neste episódio, chegando esta "epidemia”, inclusive, ao Canadá (VIOLÊNCIA..., 1999).

- E no Brasil, matéria publicada em 25/04/99 indica que apenas neste ano, foram registradas oito mortes nos colégios públicos de São Paulo - “A baixa qualidade da educação e a falta de efetivo policial contribuem para o aumento das agressões" (GONZALES; TÓFOLI, 1999)." 
Em paralelo a toda esta discussão pela mídia à respeito do envolvimento de adolescentes em atos de violência, surgiram discussões sobre a questão da falta de punição aos menores de 18 anos (FERREIRA, 1999). A diminuição da maioridade penal para 14 anos, foi discutida e aprovada pelo Congresso dos EUA, em maio de 1997; projeto de lei semelhante (porém, com diminuição para 10 anos) foi anunciado pelo governo britânico em dezembro de 1997. Em 11/03/98, foi publicado, também, pelo Jornal da Tarde, que o ministro da Justiça do Japão solicitou a especialistas que estudassem reformas legais para punir menores de 14 anos, que cometam crimes graves. O pedido surgiu após uma série de ataques à facadas nas escolas japonesas e, segundo a polícia, a onda de criminalidade infantil e juvenil não estaria, apenas, nos incidentes na escola (GOVERNO..., 1998).

No Brasil, esta discussão vem ganhando cada dia mais espaço, ,principalmente, neste momento, em que estão sendo analisadas as mudanças no código penal (LUIZ, 1998). Mas este assunto ainda é muito controverso e tem causado polêmicas.

Diante de toda esta discussão sobre o aumento dos crimes envolvendo adolescentes e da questão da maioridade penal, o próprio papel da FEBEM tem sido questionado:

Em 21/07/96, foi publicado pelo Jornal da Tarde uma reportagem sobre "As duas faces da FEBEM"; a equipe de reportagem do jornal havia passado dois dias na Instituição, não tendo visto nada de errado. Porém, segundo declarações de um funcionário, tudo havia sido mascarado (AUGUSTO, 1996).

Outras duas matérias (SOUZA, 1996; CRÍTICAS, 1996) referem-se à visita realizada por um desembargador em 20 de setembro de 1996, a duas unidades da FEBEM, de onde "saiu chocado com a ineficiência do Estado no trabalho de ressocialização dos infratores".

Em reportagem de 18/02/98, divulgou-se a denúncia de dois promotores que acusaram a Instituição de estar emitindo relatórios precipitados e equivocados, atestando uma rápida recuperação do adolescente para influenciar a Justiça a liberá-lo, com a finalidade de diminuir a superlotação (CAMPOS, 1998a). Tal acusação foi prontamente rebatida e divulgada no dia seguinte, porém, confirmando a incapacidade 
do Estado em atender o número elevado de adolescentes que são privados de liberdade diariamente (CAMPOS, 1998b; FERREIRA, 1999).

Observamos que, em cada sociedade, levantam-se hipóteses diferentes a fim de explicar o aumento da violência, especialmente, da criança e adolescente. O EUA, por exemplo, tem livre e amplo acesso às armas de fogo, sendo não apenas permitido seu uso por crianças e adolescentes, mas em alguns Estados, até estimulado (FERREIRA, 1999).

Já no Japão, alguns psicólogos têm atribuído o aumento da violência nas escolas ao rígido e competitivo sistema educacional, além da disseminação dos videogames (jogos eletrônicos), considerados violentos e instigadores (FERREIRA, 1999).

No caso do Brasil, segundo uma pesquisa realizada pela Faculdade de Saúde Pública da USP (ADORNO, 1997), ele não considera a estrutura familiar causadora de crianças em situação de rua, mas a falta de locais públicos de lazer, cultura e educação, que, segundo ele, deveriam preencher o tempo ocioso desses jovens (LOZANO, 1997).

A UNESCO (1997) realizou uma pesquisa com 401 estudantes de Brasília de 14 a 20 anos, da classe alta que constatou como resultado que, estes jovens, são alheios à política, ociosos e individualistas. Este comportamento conformista e individualista, estaria levando-os à violência e ao uso de drogas (TÓFOLI, 1997).

Em um estudo realizado pela Associação dos Advogados Criminalistas (Acrimesp), onde foram pesquisados 416 documentos (inquéritos e processos em andamento na Grande São Paulo, no período entre maio e novembro de 1997), observou-se que os adolescentes tiveram participação em $74 \%$ dos crimes relatados; foram entrevistados 65 adolescentes entre 13 e 17 anos; todos admitiram ser usuários de drogas, segundo reportagem divulgada no JT. Além disto, dos 47 que sabiam quem era o pai, a mãe ou ambos, $31(65,96 \%)$ disseram que os pais eram dependentes de álcool ou drogas e $26(55,32 \%)$ informaram que os pais já tiveram algum tipo de antecedente judicial (ESTUDO..., 1998).

As publicações médicas já vêm apontando o problema da violência entre adolescentes há alguns anos (CDC, 1993). Um estudo realizado entre alunos de uma 
escola secundária, na cidade de Nova York, mostrou que a exposição à violência (testemunhar atos de violência) é grande entre os adolescentes de áreas urbanas e alguns tipos específicos de violência têm uma associação significativa com o desenvolvimento de problemas mentais secundários como pensamento suicida, tentativa de suicídio e uso de álcool (PASTORE, 1996).

Em outro estudo, realizado com adolescentes de escolas da Califórnia e Oregon, observou-se que fatores demográficos, ambientais e comportamentais contribuem para atitudes violentas, havendo uma ligação mais forte entre violência, uso de drogas e deliqüência, além de apontar a necessidade de fortalecimento de instituições como a família e a escola (SANER; ELLICKSON, 1996).

A associação entre comportamento violento (mais forte para brigas e uso de arma branca do que para suicídio) e uso de substâncias como álcool ou drogas ilícitas, é apontada em outro estudo, realizado com estudantes secundários no Texas (GRUNBAUM., 1998).

Podemos questionar as condições em que foram realizadas estas pesquisas, bem como os seus resultados. Porém, não nos sentimos confortáveis em omití-las. 


\subsection{Vulnerabilidade}

Por vulnerabilidade entenda-se o conceito pelo qual um indivíduo, ou população, encontra-se sob risco de determinada situação e, apesar de ciente e consciente desta situação de risco, tem pouco ou nenhum controle sobre ela.

A vulnerabilidade é um dos maiores obstáculos que o trabalho preventivo encontra junto às populações de crianças e adolescentes. Tome-se o crescimento e desenvolvimento como fenômeno biológico e universal do jovem e concluir-se-á que o mesmo tem sido tratado de uma forma estereotipada na educação e saúde, pois há uma série de limitações, referentes a instrumentos, com a finalidade de transformação de comportamento. (AYRES, 1996).

Quanto às limitações citadas, encontra-se no estudo de MOORE e ROSENTHAL (1992), citações claras, quando os autores analisam tópicos das entrevistas tais como romance, amor, relacionamentos sexuais, valores e comportamento, concluindo que a dimensão da sexualidade do adolescente oferece uma tendência para o sexo desprotegido, que o conduz, invariavelmente, a ser um indivíduo vulnerável ao vírus HIV e outras doenças sexualmente transmissíveis.

A produção teórica apresentada, como contribuições psicanáliticas ao adolescente, neste estudo, atesta a indissociabilidade social, cultural e psicológica para a saúde desta camada populacional.

O não usar camisinha para esta população está ligado a um dos fatores como sendo um produto caro diante da fome que se faz presente. Poder-se-ia dizer que os programas de prevenção distribuem gratuitamente camisinhas. Porém, fica aqui presente um questionamento:

O número e a forma de distribuição é satisfatória? Não (FERNANDES,1998).

Sabe-se que esta não é a única forma de se resgatar a particularidade da identidade social e cultural destas crianças e adolescentes capazes de serem vulneráveis à transmissão do vírus HIV (AYRES, 1996), porém, conscientemente, torna-se importante discutir e buscar soluções viáveis para esta população. 
Conceitos como: FATOR, GRUPO e COMPORTAMENTO DE RISCO já são muito conhecidos nas estratégias de controle epidemiológico da doença . O conceito de RISCO tem apresentado custos técnicos, sociais e políticos superiores a benefícios, pois o preconceito em relação aos GRUPOS ou COMPORTAMENTOS de risco são os exemplos de efeitos colaterais do uso deste conceito (AYRES, 1996).

DE PALMA et al. (1996) processa a vulnerabilidade através de imagens e um diferente interagir com a vulnerabilidade no gênero, ou seja, a mulher a percebe com crescimento significativo ao ler os sintomas da doença, enquanto que o homem a percebe quando imagina os sintomas desta doença.

A partir do diagnóstico da situação do HIV/AIDS foi criado nos Estados Unidos uma aproximação preventiva à epidemia da AIDS, ou seja, a noção da vulnerabilidade que estabelece uma síntese com conceitos a respeito de política-social e institucional, comportamentos de indivíduos, grupos e nações suscetíveis à infecção do vírus HIV. Esta noção de vulnerabilidade não visa somente àquele que tem chances, através de seu comportamento, de se expor à AIDS, mas sim todos os indíviduos com características individuais e sociais de seu cotidiano capazes de conduzirem-se à situações, já, conhecidas (transmissão sexual, uso de drogas, transfusão sanguínea e transmissão vertical) (AYRES, 1996).

Dentre esses aspectos de vulnerabilidade à AIDS ligados à adolescência, destaque-se, primeiramente, a sexualidade apresentada por estes jovens que é aqui entendida como uma construção cultural (AYRES, 1996), onde o exercício da sexualidade implica em "aprendizados" e possibilidades sociais concretas de conceitos e atitudes que varia de grupo para grupo em diferentes países. Por exemplo, ser ou não ser homossexual nos Estados Unidos, oferece uma maior chance de tomar conhecimento se a pessoa está ou não vulnerável ao vírus HIV, pois o ativo/passivo demonstra uma maior possibilidade aos padrões de práticas sexuais com relação estreita à epidemia da AIDS.

Segundo SCHERER e RIBEIRO (1997), desde os anos 60 presenciam-se discursos com prós e contras sobre descriminalização de vários comportamentos chamados de DELITOS incluindo-se a homossexualidade, onde o ASSUMIR-SE homossexual (HOPCKE, 1993) é o estabelecimento de uma personalidade própria e 
indivividual, que nas sociedades ocidentais faz com que o indivíduo tenha um longo período de inconsciência quanto a sua orientação sexual, fazendo-o sentir-se como um enigma a ser desvendado.

Falar sobre vulnerabilidade dos homossexuais no ocidente é muito difícil, pois embora homossexualismo não seja mais considerado como um desvio sexual (OMS, 1993) os mesmos ainda fazem passeatas a fim de que sua opção sexual seja, não só respeitada, mas considerada uma opção de vida (Jornal do Conselho Regional de Psicologia, 1999; Conselho Federal de Psicologia, 1999).

Ainda dentro desta linha cultural, no capítulo sobre personalidade do adolescente, escreve-se sobre a intranquilidade de identidades sexuais (AYRES, 1996; ABERASTURY, 1981; STRAUS, 1994) associada aos grupos destes adolescentes (REICH, 1988; Associação Psicanalítica de Porto Alegre, 1997; STRAUS, 1994; WINNICOTT, 1995), que torna possível conhecer a verdadeira construção sóciocultural da vida sexual do adolescente. Faz-se necessário entender este perfil para compreender realmente a epidemiologia da AIDS de cada país, ou melhor, as atitudes e crenças individuais frente à esta doença (PARKER e DANIEL, 1991; KIPKE et al., 1995). Mas, ligado à construção sócio cultural da vida sexual, está a contribuição da linguagem dos verbos COMER $\boldsymbol{e} \boldsymbol{D A R}$ no Brasil.

Esclarecendo-se melhor sobre estes verbos e , iniciando, com COMER, podese afirmar que é uma dominação simbólica descrevendo sobre o ato de penetração sexual ,comumente usado pelo brasileiro(a); o verbo $\boldsymbol{D A R}$ descreve o ato de ser penetrado.

COMER sugere um ato de dominação (machismo) e $\boldsymbol{D A R}$ implica uma forma de submissão( PARKER e DANIEL, 1991).

Com PARKER (1991) e AYRES (1996) acreditamos ter oferecido a contribuição na construção sócio-cultural sexual da realidade demográfica do Brasil.

Concordamos com AYRES (1996) quando este diz que uma frente de investigação está se abrindo, atualmente, ou seja, a associação entre vulnerabilidade à epidemia e violência. Ela é explicitada com a diminuição da auto-estima nestes 
indivíduos, que apresentam chances menores de proteção, tornando-se vulneráveis ao vírus da HIV.

Essa associação, acima descrita, conduz ao caráter político da discussão da vulnerabilidade (AYRES, 1996). Embora, muitos dos adolescentes da população estudada conheçam o valor real da violência através de sua própria família, que termina por gerar seus distúrbios emocionais e,consequentemente, maiores riscos à saúde (EVELYN e FINE;1991). Esta violência à nível individual, produto de uma família, comunidade, questões cotidianas de cidadania ou de política social (AYRES, 1996; STRAUS, 1994), faz com que se entenda melhor a vulnerabilidade à AIDS.

O Estado não gasta dinheiro suficiente nesta camada social e no sistema prisional, sendo que quando o maior comete algo é chamado de crime ou homicídio ou latrocínio ou roubo ou estupro ou...para o menor é usado a palavra INFRAÇÃ , mas esse menor tem uma punição e não uma ação sócio-educativa com um caráter preventivo ou de recuperação (Associação Psicanalítica de Porto Alegre, 1995).

É oportuno introduzir o recorte do discurso (expontâneo) de um(a) dos(as) entrevistados(as) e algumas considerações à respeito do mesmo, baseadas no artigo de AYRES (1998) :

- "a gente dorme juntos porque tem medo que no meio da noite a polícia chegue, bata na gente e jogue dentro do camburão.”

1) pode-se dizer que esses(as) adolescentes escolheram dormir juntos e assumir um comportamento de risco?

2) esse comportamento é inadequado?

3) Onde está o verdadeiro risco: na infecção do vírus HIV ou na violência exposta?

4) Qual a alternativa para aquele momento? 
Não se aceita a situação de risco como condição constitutiva da pobreza, da miséria, do desamparo da política social, mas sim, estar frente à uma situação real de vida onde o risco se faz presente com questões acima apresentadas( AYRES, 1998).

Como evitar este comportamento de risco?

O sexo inseguro é o único prazer que estes(as) jovens têm. Como pedir à eles(as) que usem CAMISINHA nessa hora tão especial e única de suas vidas? (STRAZZA, 1997)

AS DROGAS E O SEXO SÃO, SEM DÚVIDA, O ESCAPE QUE ELES(AS) TEM DA REALIDADE QUE LHES É MUITO CRUEL, OU MELHOR, SUAS VIDAS.

ELES(AS) TÊM MUITOS PROBLEMAS EM RELAÇÃO À POBREZA QUE FAZEM SOMBRA À AIDS.

O que realmente PREOCUPA-os(as) é SABER ONDE IRÃO DORMIR À NOITE E SE ACORDARÃO com vida. 


\title{
2. OBJETIVOS
}

\subsection{Objetivos Gerais}

Determinar a influência do uso de drogas e do comportamento sexual na vulnerabilidade para HIV/AIDS e suas diferenças em adolescentes infratores do gênero feminino e masculino internados na FEBEM de São Paulo, a partir de dados de soroprevalência para HIV, questionário de comportamento de risco e grupos focais.

\subsection{Objetivos Específicos}

- Determinar a soroprevalência de anticorpos contra o HIV e o vírus da hepatite $\mathrm{C}(\mathrm{HCV})$ nesta população;

- Verificar aspectos culturais e hábitos que potencialmente influam na vulnerabilidade para o HIV/AIDS, a saber:

\author{
- promiscuidade sexual \\ - submissão feminina e machismo \\ - uso e abuso de drogas \\ - escolaridade \\ - relações familiares \\ - contribuição da mídia
}




\section{CASUÍSTICA E MÉTODOS}

Este é um estudo sorológico transversal não-anônimo, acoplado a um questionário de comportamento.

\subsection{População}

A população estudada foi constituída de adolescentes internados na FEBEM da cidade de São Paulo, em dezembro de 1994 (adolescentes masculinos) e em março de 1995 (adolescentes femininas), assim distribuídos:

\section{Adolescentes Masculinos}

- FEBEM QUADRILÁTERO TATUAPÉ - (12 unidades) trabalhamos com todos que se encontravam internados naquele momento e consentiram em participar de nosso estudo;

\section{Adolescentes Femininas}

RODOVIA DOS IMIGRANTES - (3 casas): Trabalhamos com todas as casas, ou seja, com as meninas que se encontravam internadas naquele momento e consentiram em participar de nosso estudo;

- casa 1: triagem da chegada ;

- casa 2: furtos, roubos, vícios em drogas, traficantes, etc.;

- casa 3: homicidas.

Estavam internados no Quadrilátero Tatuapé e na Rodovia Imigrantes, na época do estudo, com idades entre 12 e 21 anos, 1122 meninos e 93 meninas. Porém, 
10 meninos e 6 meninas se recusaram a fazer a sorologia, participando de outras partes, mas não incluidos nos resultados finais.

Portanto este estudo compreendeu 1112 meninos e 87 meninas.

O número menor de meninas explica-se pelo fato de que, na época de nosso estudo (1995), a Imigrantes era a única unidade feminina, EU-4, com capacidade de 100 meninas, divididas em 3 casas.

No presente momento (1999), essa unidade não existe mais, pois após a última rebelião, as mesmas foram transferidas para outras unidades.

Atualmente, temos :

-UAP 3 , Rua da Alegria com capacidade para 50 ocupantes;

-2 internatos: Franco da Rocha e Parada de Taipas com 40 vagas;

-EU 6, 1 unidade para semi-liberdade com 31 vagas;

-1 unidade em Campinas para atendimento provisório com 12 vagas.

Segundo informações da FEBEM, as unidades e internatos citados estão com lotação acima da capacidade, mas, mesmo assim, o número de meninas é muito desprorcional ao de meninos, sendo que em abril de 1998 tínhamos:

$-3,42 \%$ feminino x $96,58 \%$ masculino.

Todos considerados em regime de privação de liberdade.

\subsection{Consentimento}

Recebemos um convite da Profa. Therezinha Fram ( Secretária Estadual da Criança, Família e Bem-Estar Social - 1994 ) para realizar este estudo.

Para tanto obtivemos as seguintes autorizações: 
- 1) Dr. José Alberto Weiss de Andrade - Presidente do Tribunal de Justiça do Estado de São Paulo - 1994;

Apesar de nosso estudo não apresentar riscos para os indivíduos que compõe a casuística do projeto proposto e se tratar de uma pesquisa epidemiológica com indivíduos menores de 21 anos de idade, sob tutela do Estado, internados por delitos variados, o consentimento para realização das entrevistas e coletas de sangue foi obtido do Presidente do Palácio da Justiça do Estado de São Paulo, responsável legal por este grupo adolescente, através da exposição dos objetivos do presente trabalho para a Secretaria do Bem-Estar do Menor, responsável pela FEBEM, que intermediou o contato com aquela autoridade (vide cópia do documento em anexo).

2) Comissão de Ética em Pesquisa da Faculdade de Medicina da Universidade São Paulo - 1994.

3) Menores detidos na FEBEM: LIVRE e ORAL dado pelos meninos(as) a mim, que estive em campo, em conversa com pequenos grupos no refeitório de cada unidade, explicando o que era uma pesquisa e o objetivo; a importância em se fazer a sorologia (com palavras acessíveis) e, foi dado o livre arbítrio de participação. Essa reunião era realizada sem a presença de segurança, monitores e diretores. A nossa intenção era evitar qualquer tipo de constrangimento .

Eram dados 3 possibilidades de participação:

- $\quad$ - realizar somente a sorologia;

- realizar a sorologia e/ou questionário;

- realizar a sorologia e/ou grupo focal.

Foi garantido o sigilo das unidades, respostas individuais e entrega de resultados.

Os que consentiram na participação foram alertados que receberiam os resultados, da sorologia pela equipe médica da FEBEM e assim, registraram nome e data de nascimento num protocolo individual para receberem os resultados de seus exames. 
Queremos alertar sobre a reclamação destes meninos(as) referente à resultados sorológicos, pois segundo eles (as), ao entrarem na FEBEM são obrigados a fazerem o teste HIV, porém eles(as) não ficam sabendo do resultado.

\subsection{Questionário}

Inicialmente foi realizado um questionário piloto com 20 meninos. O mesmo foi feito "face- to - face" (CATANIA et al., 1990) por:

2 MÉDICOS - 1 sexo feminino (pediatra) e 1 sexo masculino (especialista em drogas);

1 ENFERMEIRO - docente da Faculdade de Enfermagem da Universidade São Paulo.

1 PSICÓLOGA - Pesquisadora de Comportamento de Risco da Universidade de São Paulo.

Após realizadas modificações, alunos das Faculdades de Educação e de Medicina da Universidade São Paulo foram treinados para aplicar o questionário. Este questionário versava sobre os seguintes tópicos (Anexo, páginas I a X):

- idade, escolaridade

- comportamento sexual

- uso de álcool

- uso de drogas ilícitas

- doenças sexualmente transmissíveis

Além disso, foi feita uma Ficha $\boldsymbol{G O}$ (histórico ginecológico e obstétrico) para ser anexada ao questionário da FEBEM FEMININA e os(as) monitores(as) foram instruídos a aplicar este conjunto de perguntas para as meninas que já tivessem tido relação sexual penetrativa (Anexo página XI). 


\subsection{Sorologia}

Coleta

Uma amostra de sangue de cada indivíduo foi colhida em tubo seco de $10 \mathrm{~mL}$, pelo sistema Vacutainer® (coleta a vácuo), por venopunção braquial.

Após a coleta aguardava-se a coagulação e retração do coágulo por período de 1 a 3 horas, a partir do qual cada amostra foi centrifugada a 3.000 rotações por minuto em centrífuga de mesa. O soro resultante foi então separado em 2 alíquotas identificadas com o código do indivíduo e congeladas a $-20^{\circ} \mathrm{C}$, conservadas assim até a análise sorológica.

Análise sorológica

A determinação da presença de anticorpos contra o HIV no soro de cada adolescente foi feita por técnica comercial de enzimaimunoensaio (ELISA) (HBK 416 Hemobio HIV1, EMBRABIO SA, São Paulo, Brasil). Os casos com sorologia positiva foram confirmados por técnica comercial de imunoblot (New LAV Blot I Ab, Sanofi Pasteur SA, França).

A determinação da presença de anticorpos contra o vírus da hepatite C (HCV) no soro dos adolescentes foi feita utilizando-se técnica comercial de ELISA (HBK 425 Hemobio HCV, EMBRABIO SA, São Paulo, Brazil). Para os soropositivos foi feita a confirmação com técnica comercial de imunoblot (INNO-LIA ${ }^{\mathrm{TM}} \mathrm{HCV}$ Ab III, INNOGENETICS N.V., Ghent, Bélgica).

\subsection{Grupo focal}

O GRUPO FOCAL (ALMEIDA, 1970; KAY et al., 1970; SKINNER, 1972, HOWARD, 1993), com no máximo com 10 adolescentes, foi coordenado por um médico e uma psicóloga da equipe. 
Eram ouvidos os conhecimentos, atitudes, crenças e hábitos sobre a transmissão do HIV.

Após a correção e o acréscimo sobre o conhecimento era feito a demonstração do uso correto da camisinha.

Todos(as) recebiam uma camisinha ao participarem deste grupo, sendo que, apenas duas unidades deixaram as camisinhas ficarem com os(as) detidos(as), pois alegaram na época que dentro da FEBEM não há sexo, portanto a camisinha iria para os pertences pessoais, que são entregues na saída deles(as).

\subsection{Análise Estatística}

Com a finalidade de verificar se as diferenças de gênero encontradas a partir das variáveis obtidas através do questionário eram estatisticamente significativas, realizou-se o teste de $\chi^{2}$ para as seguintes variáveis: número de parceiros sexuais na vida, sexo comercial, uso de preservativo, comportamento homo/bissexual, sexo anal, uma DST na vida, parceiro sexual de risco (UDI e/ou HIV positivo). Foram consideradas diferenças significativas para $\boldsymbol{p}<0,05$.

Foi calculado também o Odds Ratio para adolescentes anti-HIV positivos, levando em consideração o gênero (feminino ou masculino) para as seguintes variáveis: idade, percepção de risco para infecção pelo HIV, número de parceiros sexuais na vida, sexo comercial, uso de preservativo sempre, comportamento homo/bissexual, sexo anal, doença sexualmente transmissível, parceiro HIV positivo, uso de álcool, uso de maconha, uso de cocaína, uso de crack, uso de inalantes, uso de droga injetável, idade que usou droga pela primeira vez, compartilhamento de seringas e sorologia para anti-HCV.

Os cálculos para estas duas análises foram realizados pelo software EPI INFO, versão 6 . 


\section{RESULTADOS}

Foram entrevistados e analisados os soros de 87 adolescentes do sexo feminino e 1122 adolescentes do sexo masculino.

A faixa etária encontrada variou de 12 a 21 anos de idade, com idade média de $16,21( \pm 1,50)$ para os meninos e $15,95( \pm 1,55)$ anos para as meninas. O nível de escolaridade encontrado para ambos gêneros foi $97 \%$ incompleto até o primeiro grau.

Os resultados da soroprevalência para anticorpos conta o HIV e o HCV podem ser observados nas Figuras 2 e 3 respectivamente.

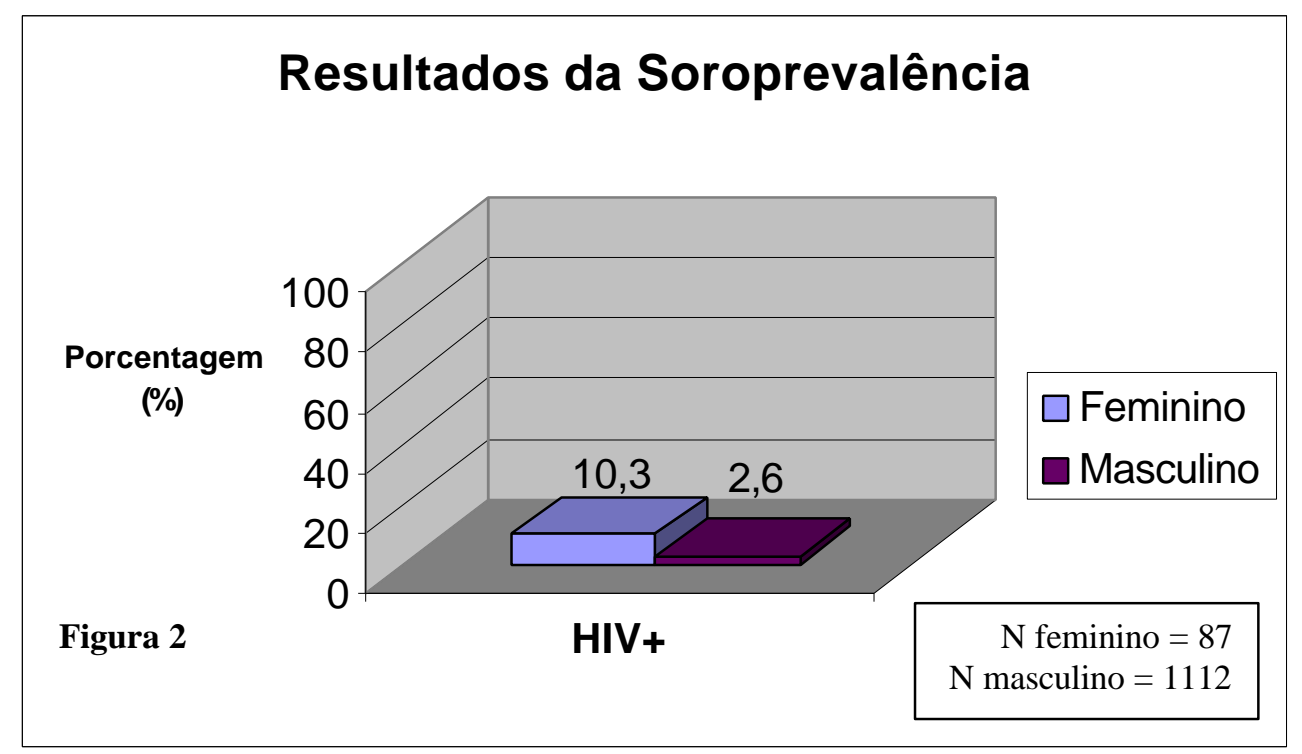

\section{Resultados da Soroprevalência}

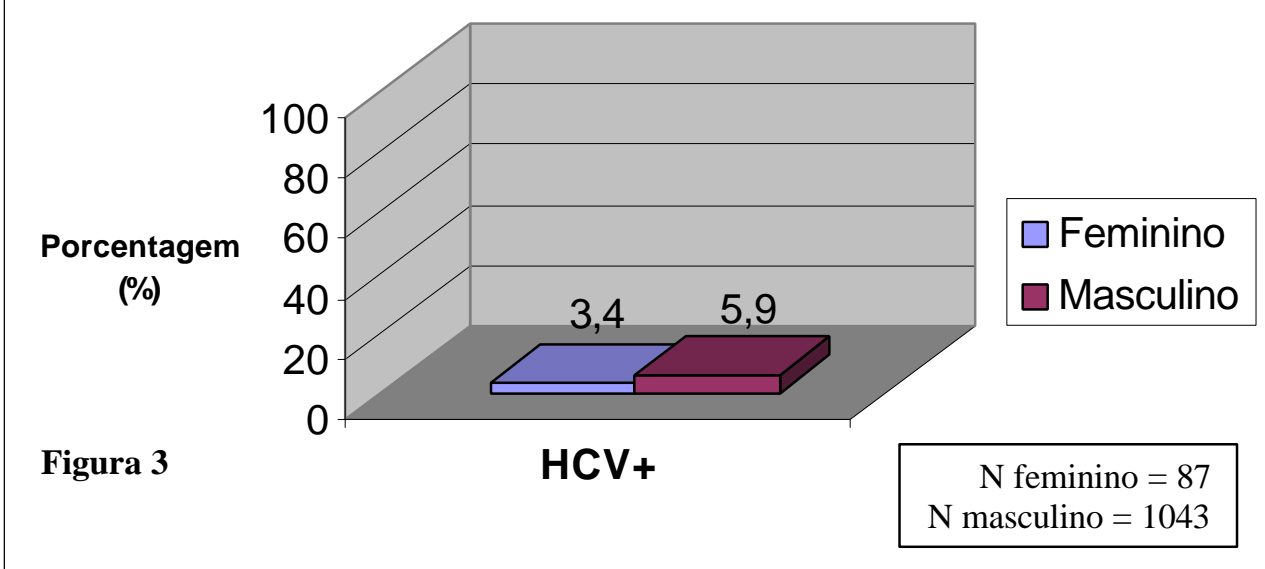


A Tabela 1 mostra a porcentagem de adolescentes de cada gênero que admitem fazer sexo dentro da FEBEM.

\begin{tabular}{|l|c|c|}
\hline Tabela 1 & Feminino & Masculino \\
\hline Sexo dentro da FEBEM & $19,7 \%$ & $2,5 \%$ \\
\hline
\end{tabular}

A Figura 4 mostra as diferenças de gênero obtidas para a opção sexual entre adolescentes na FEBEM.

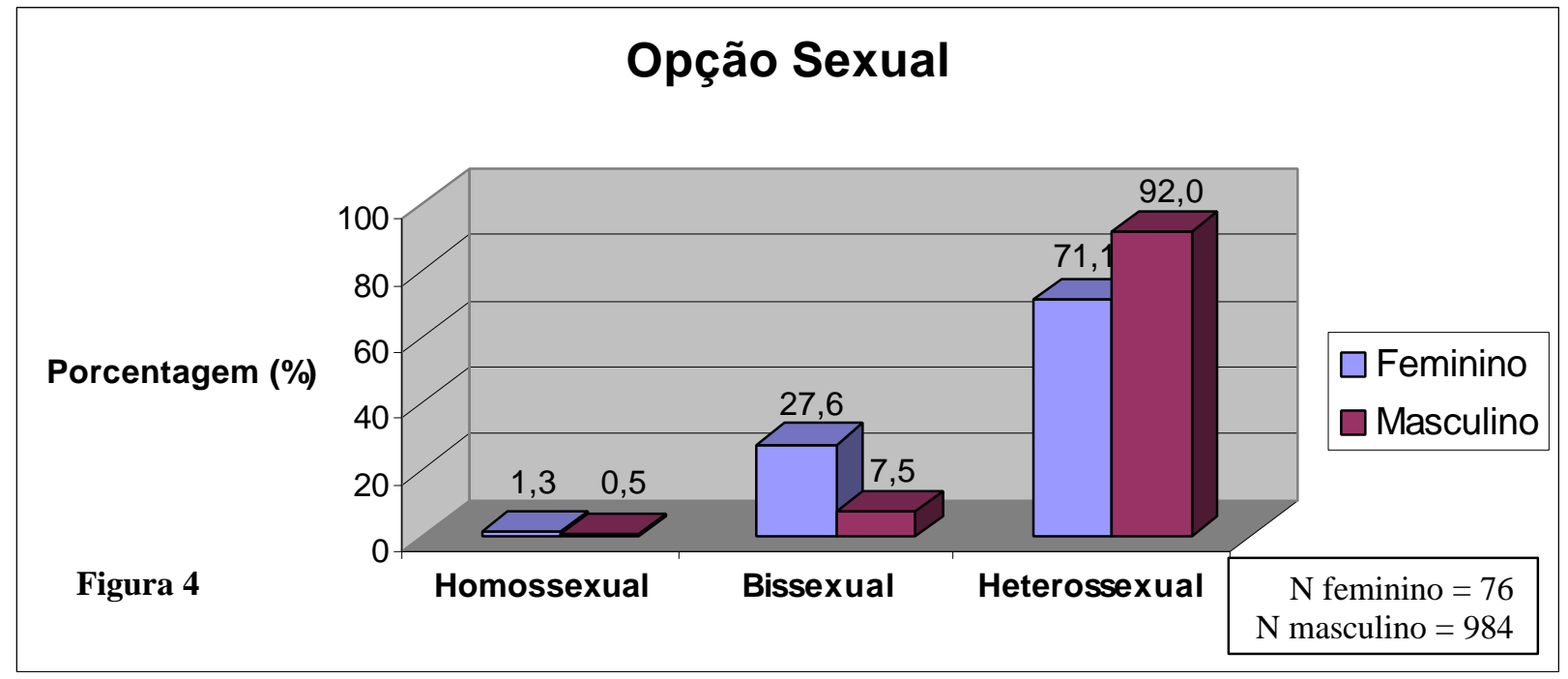

Os resultados da Ficha de dados ginecológicos das adolescentes femininas revelou os seguintes resultados: 42\% tinham ficado grávidas pelo menos 1 vez na vida; $70 \%$ tinha tido um abôrto pelo menos (54,8\% alega ter ido ao ginecologista); 8,3\% estavam grávidas na entrevista; 30,6\% tem 1 filho vivo; 5,6\% tem 2 filhos vivos. A Figura 5 mostra o uso de camisinha entre adolescentes na FEBEM.

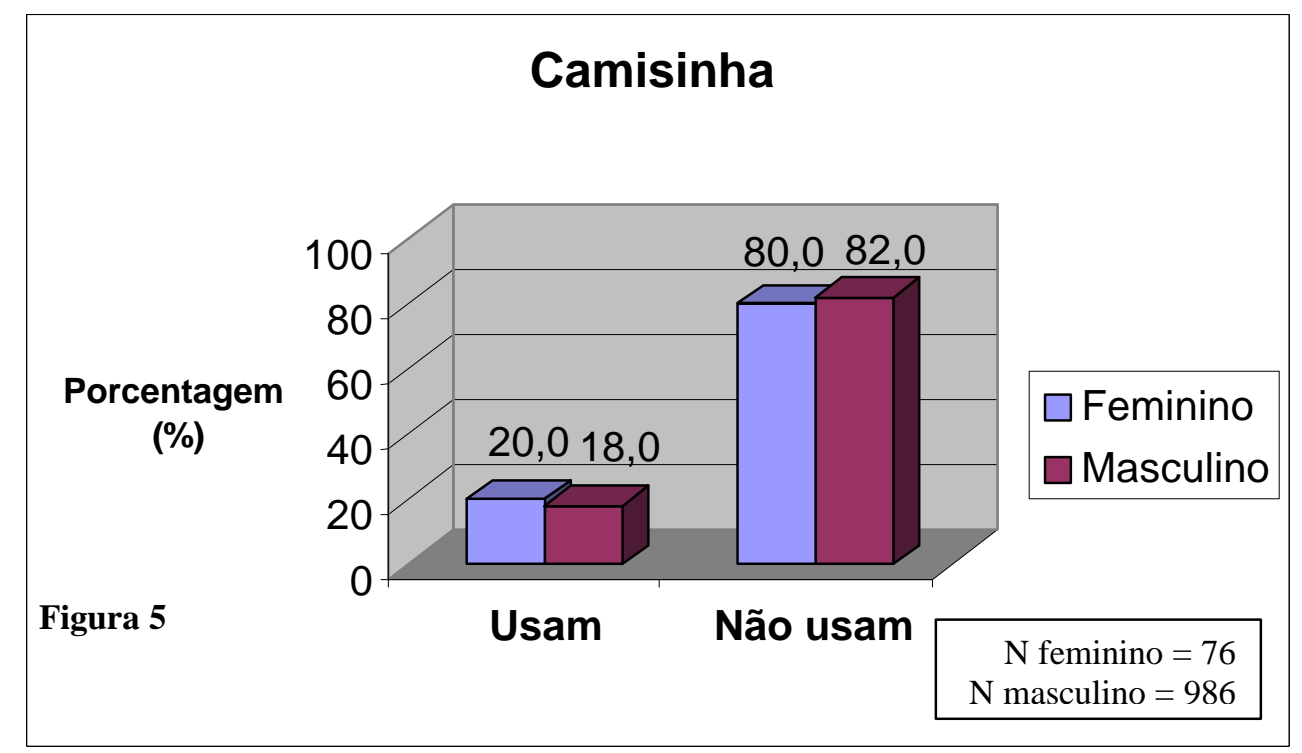


A Figura 6 mostra a porcentagem de adolescentes que já fizeram sexo penetrativo por dinheiro alguma vez na vida.

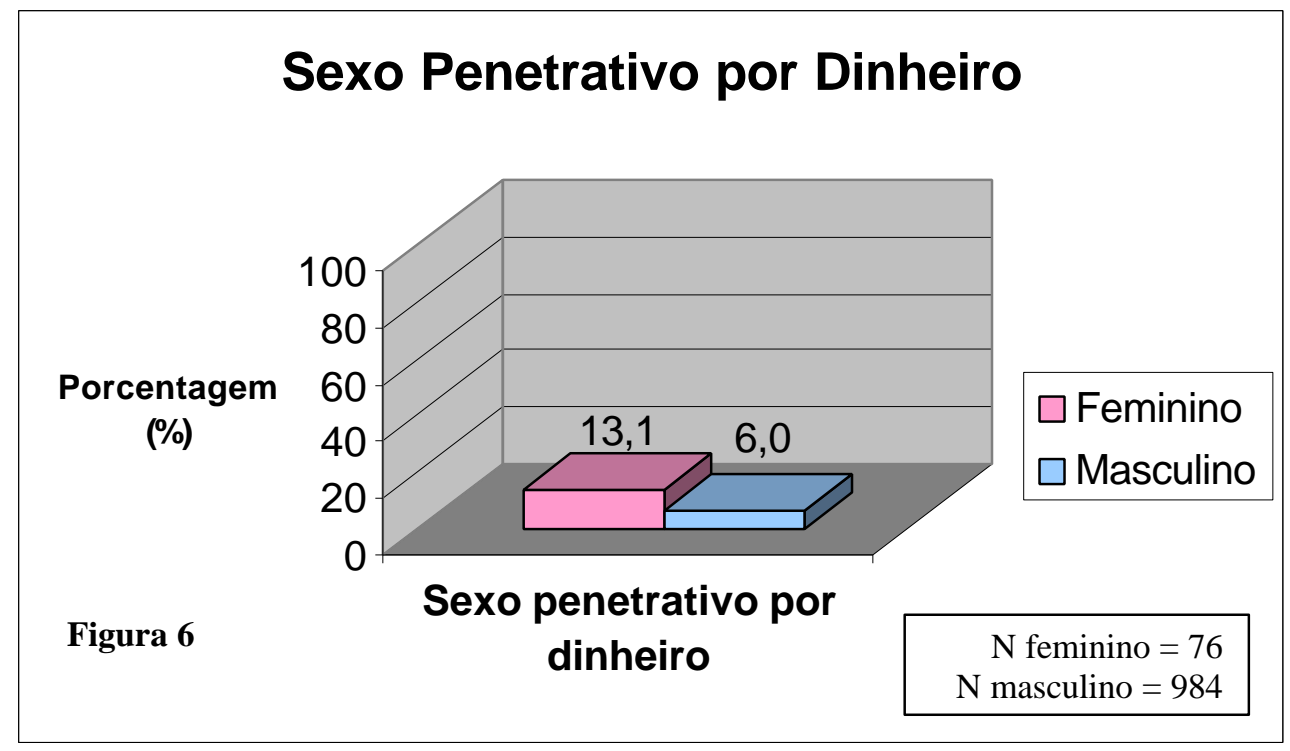

A Tabela 2 mostra a porcentagem para a variável número de parceiros na vida.

\begin{tabular}{|l|c|c|}
\hline Tabela 2 & Feminino & Masculino \\
\hline 1 parceiro(a) & $23,4 \%$ & $9,0 \%$ \\
\hline de 2 a 5 parceiros(as) & $55,0 \%$ & $39,0 \%$ \\
\hline mais de 5 parceiros(as) & $21,6 \%$ & $52,0 \%$ \\
\hline
\end{tabular}

A Tabela 3 mostra a porcentagem de adolescentes que já praticou sexo anal.

\begin{tabular}{|l|c|c|}
\hline Tabela 3 & Feminino & Masculino \\
\hline Sexo anal & $11,8 \%$ & $37,0 \%$ \\
\hline
\end{tabular}

Observação: a questão sobre sexo anal para ambos os sexos não foi perguntada diretamente. A pergunta do questionário era: Você usa camisinha com sexo anal? 
Tomamos conhecimento da BANCA que é um GRUPO DE PESSOAS, dentro ou fora da FEBEM, com o qual repartem seus ganhos. Assim por exemplo, cada um na visita recebe algo, como bolachas recheadas. Mas observamos aqueles que, além de não receberem visitas, não recebem nada. Porém, podem assim mesmo realizar trocas com alguém de sua banca que recebeu algo. Uma das moedas de troca entre pessoas da banca é o sexo.

Os ganhos, lá fora, também são trocados e quando são inexistentes, o sexo se faz presente (MASSAD e STRAZZA, 1997).

A Figura 7 mostra a porcentagem de adolescentes que já tiveram relações sexuais penetrativas.

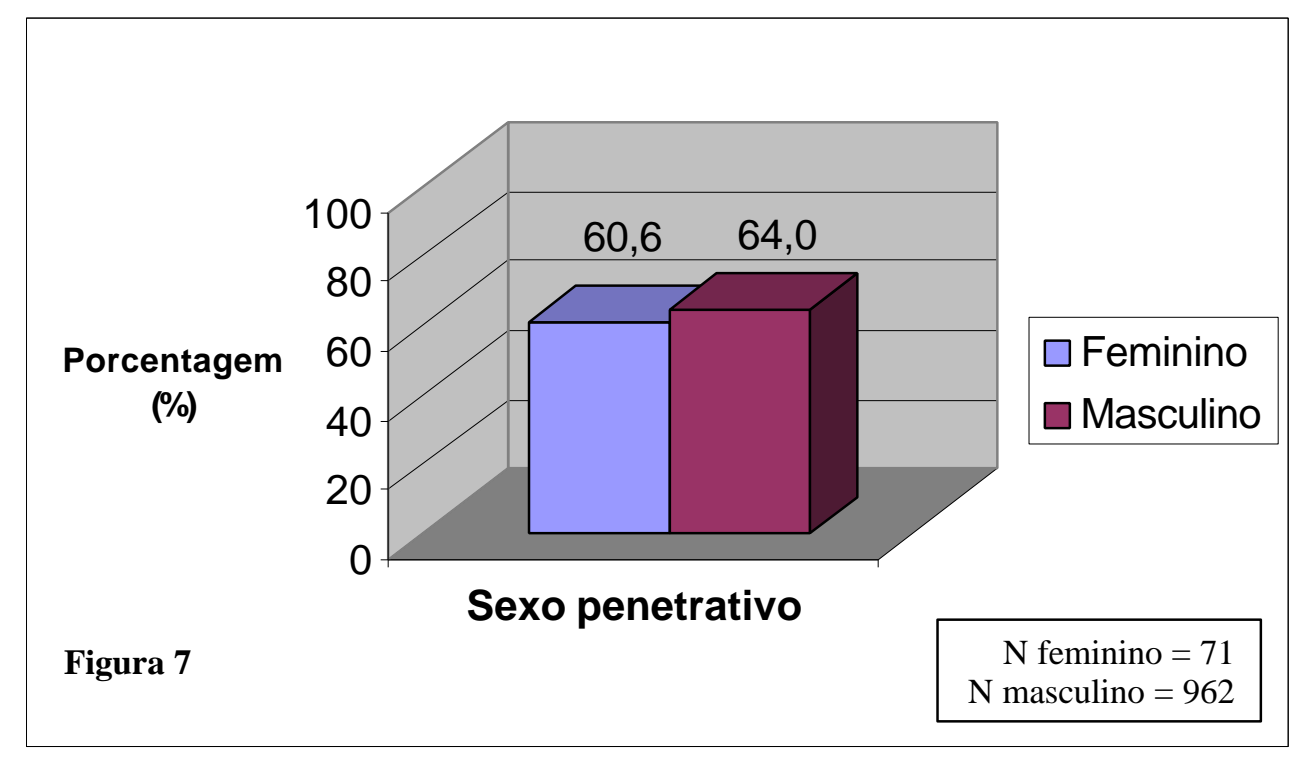

Responderam, ambos os sexos, a seguinte pergunta do nosso questionário: Quando a pessoa é da sua banca, você usa camisinha? A Figura 8 ilustra os resultados.

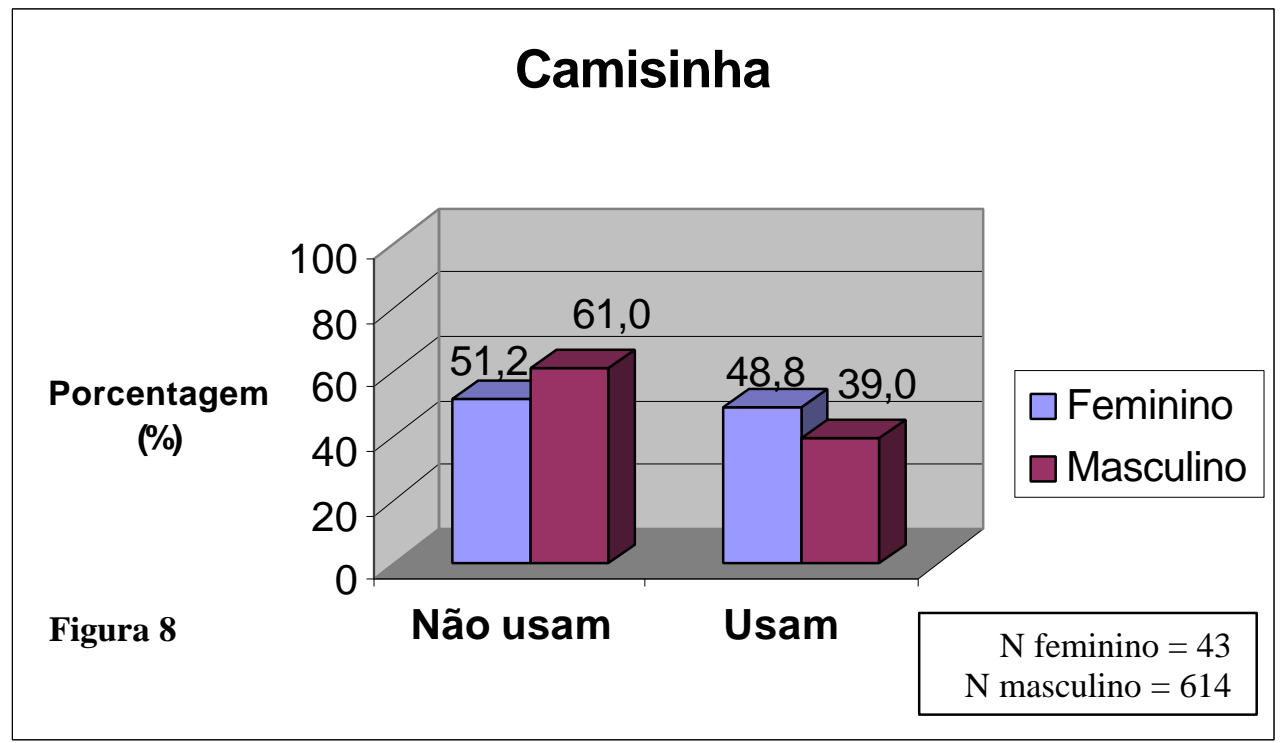


Nas respostas contamos, também, com o constrangimento das pessoas que disseram não fazer sexo com a banca. $O$ tipo de pergunta reveladora causou surpresa nós sabermos sobre a existência e o procedimento da Banca (MASSAD e STRAZZA, 1997).

Foi perguntado se já experimentaram as seguintes drogas ilícitas dentro e fora da FEBEM para ambos os sexos. Embora a FEBEM alegue que dentro dela não se use drogas, nós tivemos: 92\% (80 de 87) das meninas e 96\% dos meninos (1078 de 1122) afirmaram o uso destas drogas dentro e fora da FEBEM (Tabela 4):

\begin{tabular}{|l|r|r|r|l|}
\hline Tabela 4 & \multicolumn{1}{|l|}{ Feminino } & \multicolumn{1}{l|}{ Masculino } & \multicolumn{1}{l|}{ Feminino } & \multicolumn{1}{l|}{ Masculino } \\
& Dentro FEBEM & Dentro FEBEM & Fora da FEBEM & Fora da FEBEM \\
\hline Maconha & $8,3 \%$ & $11,5 \%$ & $87,4 \%$ & $83,0 \%$ \\
\hline Cocaína & $1,2 \%$ & $2,0 \%$ & $64,4 \%$ & $63,0 \%$ \\
\hline LSD & $0 \%$ & $0,3 \%$ & $9,2 \%$ & $3,5 \%$ \\
\hline Crack & $6,0 \%$ & $1,6 \%$ & $69,0 \%$ & $55,0 \%$ \\
\hline Haxixe & $1,2 \%$ & $1,0 \%$ & $41,4 \%$ & $37,0 \%$ \\
\hline
\end{tabular}

A Figura 9 ilustra o uso de droga injetável entre os adolescentes da FEBEM.

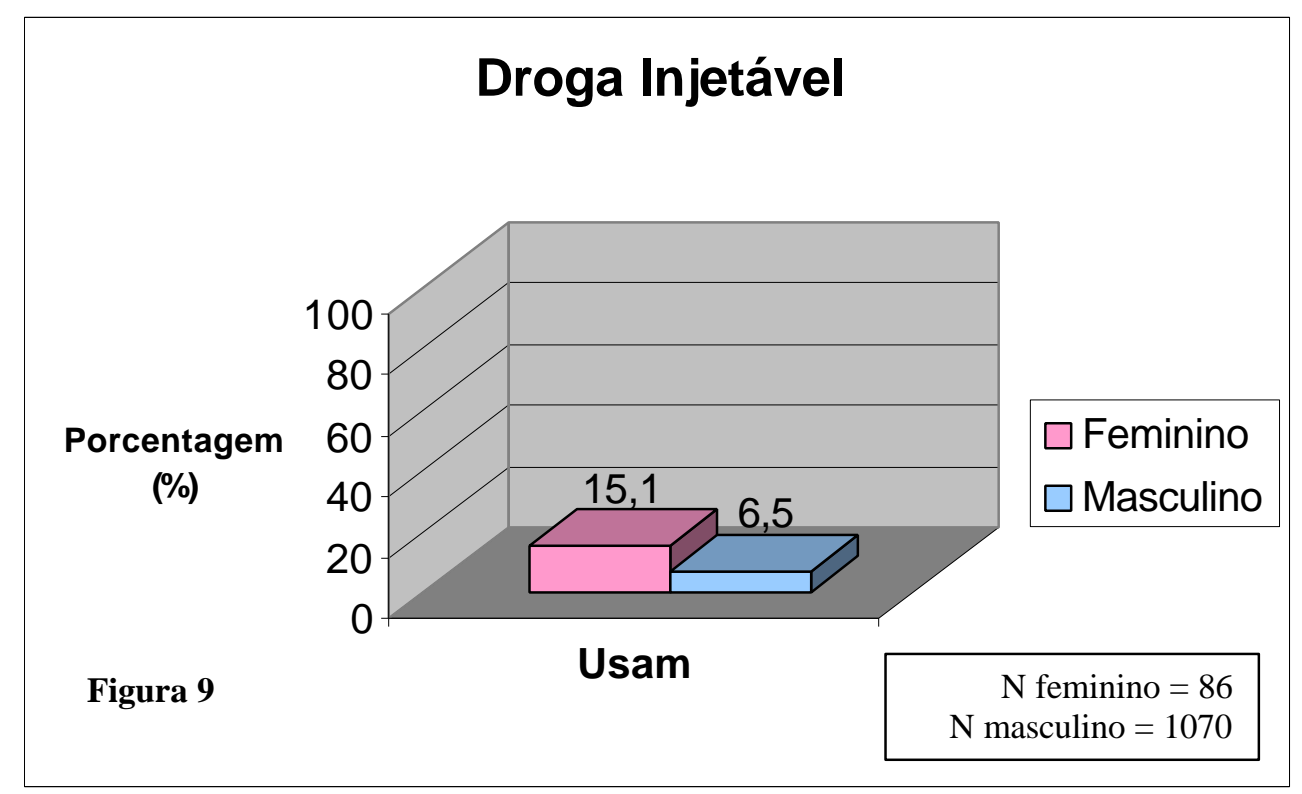


A Figura 10 mostra a porcentagem de adolescentes que compartilham seringas, entre os usuários de drogas injetáveis.

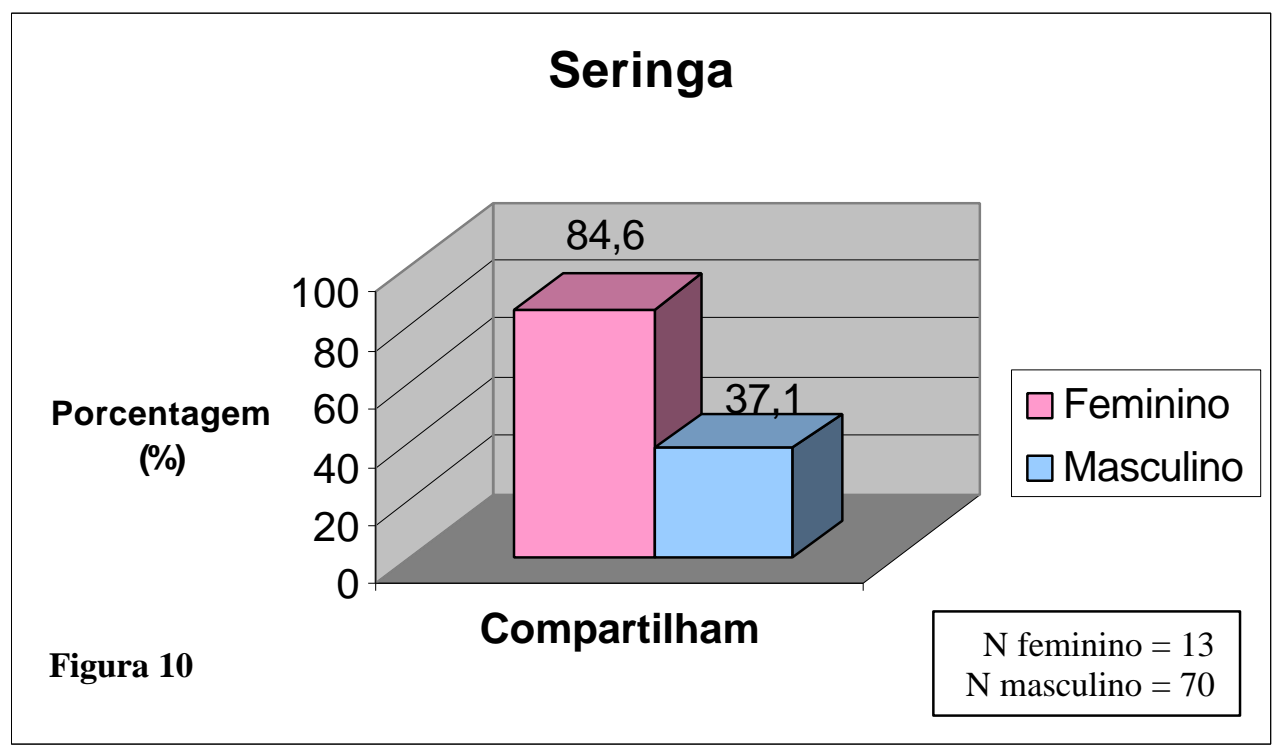

A Tabela 5 mostra a porcentagem de adolescentes que já teve parceiro sexual usuário de droga injetável.

\begin{tabular}{|l|c|c|}
\hline Tabela 5 & Feminino & Masculino \\
\hline Sim & $20,5 \%$ & $10,0 \%$ \\
\hline Não & $63,1 \%$ & $75,0 \%$ \\
\hline não sabem dizer & $16,4 \%$ & $15,0 \%$ \\
\hline
\end{tabular}

A Figura 11 mostra fração que teve Doença Sexualmente Transmissível (DST).

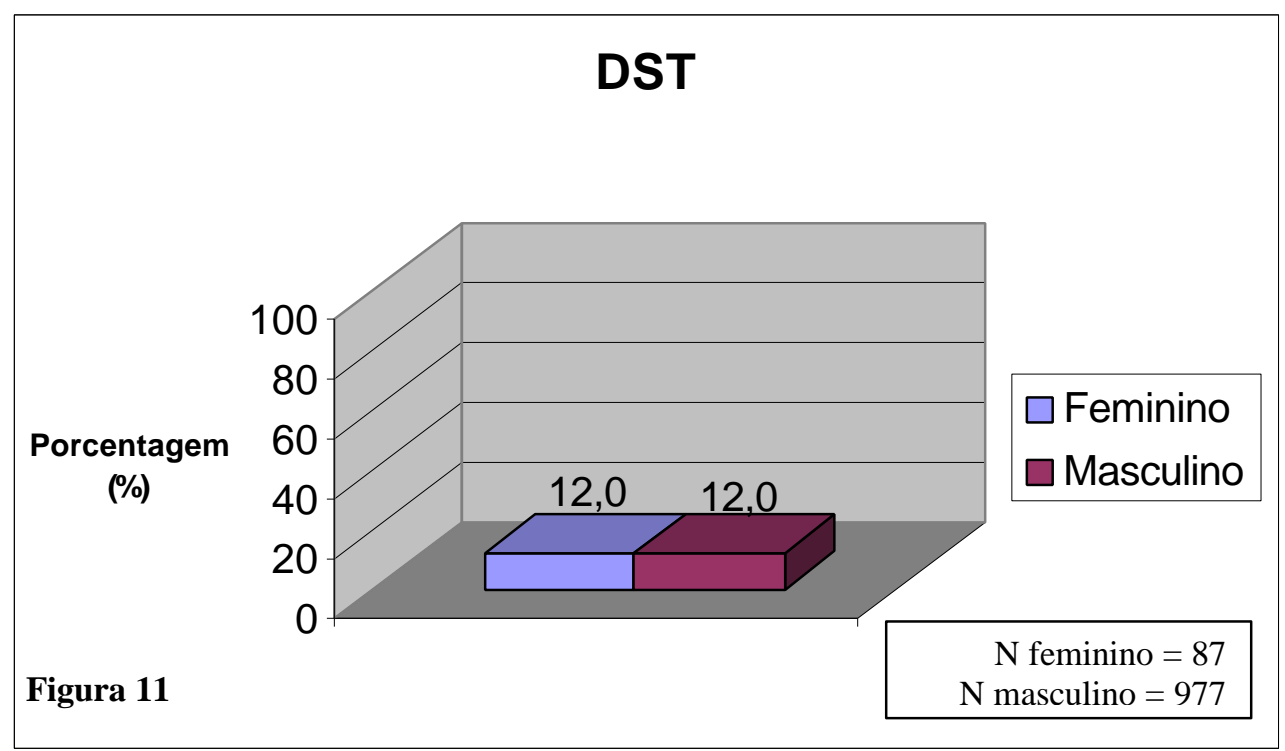


A Tabela 6 mostra porcentagem que já teve parceiro sexual com AIDS.

\begin{tabular}{|l|c|c|}
\hline Tabela 6 & Feminino & Masculino \\
\hline Sim & $10,5 \%$ & $4,0 \%$ \\
\hline Não & $56,6 \%$ & $68,0 \%$ \\
\hline não sabem dizer & $32,9 \%$ & $28,0 \%$ \\
\hline
\end{tabular}

A Tabela 7 revela como adolescentes da FEBEM obtiveram informações sobre AIDS até o momento da entrevista.

\begin{tabular}{|l|c|c|}
\hline Tabela 7 & Feminino & Masculino \\
\hline Mídia & $35,0 \%$ & $44,0 \%$ \\
\hline Amigos & $25,0 \%$ & $17,0 \%$ \\
\hline Parentes & $15,0 \%$ & $20,0 \%$ \\
\hline FEBEM & $1,0 \%$ & $15,0 \%$ \\
\hline outras fontes & $24,0 \%$ & $4,0 \%$ \\
\hline
\end{tabular}

A Tabela 8 mostra o conhecimento sobre a transmissão do HIV.

\begin{tabular}{|l|r|r|}
\hline Tabela 8 & \multicolumn{1}{|c|}{ Feminino } & Masculino \\
\hline "meladinho" (fluídos) transmite & $83,9 \%$ & $68,0 \%$ \\
\hline homem transmite para a mulher & $97,7 \%$ & $92,0 \%$ \\
\hline mulher transmite para o homem & $96,6 \%$ & $93,0 \%$ \\
\hline transmissão por sexo anal & $85,1 \%$ & $84,0 \%$ \\
\hline transmissão por sexo oral & $93,1 \%$ & $68,0 \%$ \\
\hline trasmissão por sangue menstrual & $93,1 \%$ & $86,0 \%$ \\
\hline engolir semen transmite & $87,4 \%$ & $67,0 \%$ \\
\hline pessoa com saúde pode transmitir & $89,7 \%$ & $77,0 \%$ \\
\hline
\end{tabular}


A Tabela 9 mostra algumas atitudes quanto ao relacionamento com uma pessoa com AIDS.

\begin{tabular}{|c|r|r|}
\hline Tabela 9 & \multicolumn{1}{|l|}{ Feminino } & \multicolumn{1}{l|}{ Masculino } \\
\hline não daria um abraço em alguém com AIDS & $9,2 \%$ & $21,0 \%$ \\
\hline não moraria na mesma casa & $24,1 \%$ & $29,0 \%$ \\
\hline não trabalharia junto & $18,4 \%$ & $21,0 \%$ \\
\hline não usaria mesmo banheiro & $42,5 \%$ & $40,0 \%$ \\
\hline não usaria o mesmo copo & $25,3 \%$ & $41,0 \%$ \\
\hline não apertaria a mão & $11,5 \%$ & $14,0 \%$ \\
\hline
\end{tabular}

Como se pode observar a partir dos resultados acima, a maioria destes adolescentes já teve relações sexuais penetrativas. Há diferenças flagrantes entre o grupo de adolescentes masculino e feminino em algumas das variáveis estudadas.

A Tabela 10 mostra variáveis com diferença de gênero estatisticamente significativas $(\boldsymbol{p}<0,05)$.

Tabela 10 - Diferenças de gênero com relação ao comportamento sexual

\begin{tabular}{|c|c|c|c|}
\hline Tabela 10 & $\begin{array}{c}\text { Feminino } \\
\text { Número (\%) }\end{array}$ & $\begin{array}{c}\text { Masculino } \\
\text { número (\%) }\end{array}$ & $\boldsymbol{p}$ \\
\hline Número de parceiros sexuais na vida & & & \\
\hline 1 & $18(0,23)$ & $84(0,09)$ & \\
\hline $2-5$ & $42(0,55)$ & $361(0,39)$ & $<0,0001$ \\
\hline$>5$ & $16(0,21)$ & $478(0,52)$ & \\
\hline Sexo comercial & & & \\
\hline Comportamento homo/bissexual & $10(0,13)$ & $60(0,06)$ & 0,031 \\
\hline & & & \\
\hline Sexo anal & $22(0,29)$ & $81(0,08)$ & $<0,0001$ \\
\hline & $09(0,12)$ & $363(0,37)$ & $<0,0001$ \\
\hline & & & \\
\hline Pelo menos uma DST & & & \\
\hline & $16(0,21)$ & $112(0,11)$ & 0,022 \\
\hline Parceiro sexual de risco & & & \\
\hline Usuário de DI & & & \\
\hline HIV positivo & $15(0,21)$ & $95(0,10)$ & 0,008 \\
\hline & $08(0,11)$ & $40(0,04)$ & 0,018 \\
\hline
\end{tabular}


A Tabela 11 mostra resultados do cálculo de Odds Ratio (OR) para anti-HIV positivos. Estão assinaladas em negrito OR significantes.

\begin{tabular}{|c|c|c|c|c|}
\hline \multirow{2}{*}{$\begin{array}{l}\text { Tabela } 11 \\
\text { Variável }\end{array}$} & \multicolumn{2}{|l|}{ Feminino } & \multicolumn{2}{|l|}{ Masculino } \\
\hline & $\mathrm{HIV}+$ & Odds Ratio (95\% CI) & $\mathrm{HIV}+$ & Odds Ratio $(95 \% \mathrm{CI})$ \\
\hline \multicolumn{5}{|l|}{ Idade } \\
\hline$<18$ anos & $6(0,08)$ & $0,23(0,04-1,72)$ & $19(0,02)$ & $0,42(0,18-0,99)$ \\
\hline$\geq 18$ anos & $3(0,27)$ & & $10(0,05)$ & \\
\hline \multicolumn{5}{|l|}{ Percepção de risco para infecção por HIV } \\
\hline Sim & $3(0,07)$ & $0,71(0,10-4,54)$ & $19(0,03)$ & $3,31(0,96-17,58)$ \\
\hline Não & $4(0,10)$ & & $3(0,01)$ & \\
\hline \multicolumn{5}{|l|}{ Número de parceiros sexuais na vida } \\
\hline Nenhum parceiro & $0(0,00)$ & & $3(0,03)$ & 1,00 \\
\hline 1 a 5 parceiros & $5(0,08)$ & 1,00 & $7(0,02)$ & $0,48(0,11-2,93)$ \\
\hline$>5$ parceiros & $4(0,25)$ & $3,67(0,62-19,63)$ & $14(0,03)$ & $0,91(0,25-5,02)$ \\
\hline \multicolumn{5}{|l|}{ Sexo comercial } \\
\hline Sim & $4(0,40)$ & $8,13(1,33-51,90)^{*}$ & $2(0,03)$ & $1,41(0,00-6,45)$ \\
\hline Não & $5(0,08)$ & & $24(0,02)$ & \\
\hline \multicolumn{5}{|l|}{ Uso de preservativo sempre } \\
\hline Sim & $3(0,20)$ & $2,29(0,38-12,87)$ & $8(0,03)$ & $1.39(0,55-3,42)$ \\
\hline Não & $6(0,10)$ & & $18(0,02)$ & \\
\hline \multicolumn{5}{|l|}{ Comportamento homo/bisssexual } \\
\hline Sim & $2(0,09)$ & $0,67(0,09-4,10)$ & $2(0,03)$ & $1,03(0,00-4,44)$ \\
\hline Não & $7(0,13)$ & & $24(0,03)$ & \\
\hline \multicolumn{5}{|l|}{ Sexo anal } \\
\hline Sim & $3(0,33)$ & $5,08(0,75-33,73)$ & $6(0,02)$ & $0,65(0,23-1,76)$ \\
\hline Não & $6(0,09)$ & & $18(0,03)$ & \\
\hline \multicolumn{5}{|l|}{ Doença sexualmente transmissível } \\
\hline Ao menos uma vez na vida & $4(0,22)$ & $3,59(0,63-19,17)$ & $6(0,06)$ & $2,98(1,02-8,27)^{*}$ \\
\hline Nunca na vida & $5(0,07)$ & & $18(0,02)$ & \\
\hline \multicolumn{5}{|l|}{ Parceiro sexual usuário de droga injetável } \\
\hline Sim & $1(0,13)$ & $1,18(0,00-12,89)$ & $3(0,03)$ & $1,24(0,29-4,46)$ \\
\hline Não & $7(0,11)$ & & $26(0,03)$ & \\
\hline \multicolumn{5}{|l|}{ Parceiro HIV positivo } \\
\hline Sim & $1(0,13)$ & $1,09(0,00-11,49)$ & $2(0,05)$ & $2.46(0,00-11,58)$ \\
\hline Não & $8(0,12)$ & & $22(0,02)$ & \\
\hline \multicolumn{5}{|l|}{ Uso de Álcool } \\
\hline Sim & $5(0,09)$ & $0,59(0,12-3,26)$ & $17(0,02)$ & $0,81(0,34-2,01)$ \\
\hline Não & $4(0,14)$ & & $9(0,03)$ & \\
\hline \multicolumn{5}{|l|}{ Uso de Maconha } \\
\hline Sim & $6(0,08)$ & $0,23(0,04-1,72)$ & $25(0,03)$ & $5,11(0,83-211,20)$ \\
\hline Não & $3(0,27)$ & & $1(0,01)$ & \\
\hline
\end{tabular}




\begin{tabular}{|c|c|c|c|c|}
\hline Tabela 11 - continuação & Feminino & Odds Ratio $(95 \% \mathrm{CI})$ & Masculino & Odds Ratio $(95 \% \mathrm{CI})$ \\
\hline \multicolumn{5}{|l|}{ Uso de Cocaína } \\
\hline Sim & $6(0,11)$ & $1,12(0,22-7,44)$ & $23(0,03)$ & $4,60(1,38-24,09) *$ \\
\hline Não & $3(0,10)$ & & $3(0,01)$ & \\
\hline \multicolumn{5}{|l|}{ Uso de Crack } \\
\hline Sim & $6(0,10)$ & $0,89(0,17-5,96)$ & $20(0,03)$ & $2,78(1,07-8,53)^{*}$ \\
\hline Não & $3(0,11)$ & & $6(0,01)$ & \\
\hline \multicolumn{5}{|l|}{ Uso de Inalantes } \\
\hline Sim & $5(0,09)$ & $0,56(0,11-3,08)$ & $21(0,04)$ & $3,53(1,28-12,07) *$ \\
\hline Não & $4(0,14)$ & & $5(0,01)$ & \\
\hline \multicolumn{5}{|l|}{ Uso de droga Injetável } \\
\hline Sim & $3(0,23)$ & $3,35(0,55-19,38)$ & $14(0,20)$ & $20,77(8,49-51,08) *$ \\
\hline Não & $6(0,08)$ & & $12(0,01)$ & \\
\hline \multicolumn{5}{|l|}{ Faixa etária que usou droga pela $1^{\mathrm{a}}$ vez } \\
\hline$<14$ anos & $1(0,14)$ & $0,28(0,00-7,54)$ & $8(0,24)$ & $1,60(0,42-6,19)$ \\
\hline$\geq 14$ anos & $2(0,40)$ & & $6(0,17)$ & \\
\hline \multicolumn{5}{|l|}{ Compartilhamento de seringas (UDI) } \\
\hline Sim & $3(0,38)$ & - & $10(0,40)$ & $6,67(1,57-32,68)^{*}$ \\
\hline Não & $0(0,00)$ & & $4(0,09)$ & \\
\hline \multicolumn{5}{|l|}{ Sorologia para anti-HCV } \\
\hline HCV positivo & $2(0,50)$ & $10,26(0,65-162,31)$ & $19(0,29)$ & $42,67(17,47-106,06)^{*}$ \\
\hline HCV negativo & $7(0,08)$ & & $10(0,01)$ & \\
\hline
\end{tabular}

$\mathrm{CI}=$ intervalo de confiança

* Odds Ratio significativo 


\section{DISCUSSÃO}

A epidemia da AIDS desconstruiu um processo epidemiológico que a Saúde Pública e os orgãos governamentais vinham solidificando.

É a EPIDEMIA do FINAL DO SÉCULO com os cientistas e pesquisadores do mundo inteiro se perguntando:

— "O que foi conhecido e feito até o presente momento?"

O vírus HIV é, provavelmente, o mais exaustivamente estudado na história. Um grande número de HIVs diferentes já foram isolados, clonados e sequenciados. Muitos genes do vírus e produtos de suas proteínas foram também caracterizados. Aceita-se que o próprio vírus tenha um papel fundamental no desencadeamento e propagação da doença, porém aspectos de virologia e imunologia continuam como problemas insolúveis. (PANTALEO et al.,1993).

Numa primeira aproximação às dimensões mundiais da epidemia, a OMS (Organização Mundial de Saúde) definiu a incidência em três grandes "padrões epidemiológicos":

1) padrão I - associado aos países mais desenvolvidos;

2) padrãoII - uma situação africana considerando a via heterossexual como principal transmissora;

3) padrão III - países com nenhuma ou baixa (atribuível ao contato com regiões dos padrões I e II) notificação de casos de AIDS.

Esta concepção é tida como estática, pois os padrões estão associados a diferentes distribuições de infecções por grupos e encontradas em macrorregiões do mundo (BASTOS et al., 1994). A AIDS gerou diferentes equívocos e especulações no uso popular como: “A AIDS Americana"e "A AIDS Africana”, uma contrapartida de linguagem científica com preconceitos racistas que prevaleceram na representação do mundo. Serviu também de referência e caracterização de padrão epidemiológico de 
alguns contextos em que se perguntava: "A AIDS Brasileira" seria mais "americana" ou "africana" ou existiria nos EstadosUnidos "bolsões" de padrão II coincindo com os "bolsões de terceiro mundo" e, então, sobrepuseram-se os preconceitos raciais?

Note-se que essas especulações são em cima de sugestões da OMS que tentou mapear as diferenças internacionais da epidemia da AIDS, nunca a OMS sustentou serem epidemias diferentes(BASTOS C. et al ,1994).

E como classificar um grupo como o mostrado neste estudo: adolescentes infratores cuja faixa de idade média é de 16 anos e que a educação destes jovens é incompleta no primeiro grau escolar, para ambos os gêneros, masculino e feminino?

Sabe-se que esta população confinada apresenta um momento único em sua vida, para cuidar de seus corpos, saúde, ou melhor, para uma prevenção (DIXON, 1993). Porém, concorda-se com VLAHOV et al. (1991), SHAFER et al. (1993), SHAFER (1994), ROTILY (1994), MARTIN (1994), MORRIS et al. (1995), CANTERBURY et al. (1995) com o alto risco que estes(as) adolescentes estão expostos(as) em adquirir DSTs, inclusive AIDS, estando encarcerados e realizando relações sexuais às escondidas e às pressas e, geralmente, sem camisinha.

É repetitivo acrescentar que esta população tem um alto conhecimento sobre o vírus HIV, porém com comportamento sexual e práticas cristalizadas à crenças que os(as) colocam vulneráveis à AIDS.

É importante citar que no grupo focal deste estudo, alertou-se as meninas da FEBEM quanto ao uso da camisinha e seu duplo controle oferecido: evita a gravidez indesejada e as DSTs como a AIDS. Foi questionado, quanto ao conhecimento delas, se sabiam evitar uma DST e descobriu-se em suas respostas que $4,7 \%$ teve mais que uma DST, 20,7\% disseram que não sabiam, 68,6\% alegou que o uso da camisinha previne a ter uma DST. Porém, 15,1\% delas seleciona o par ou "transa" sexualmente com "homens limpos", ao que foi perguntado:

— O que é um "homem limpo"?

Resposta:

— "Aquele que toma banho". 
É interessante notar a questão de genêro encontrada na evolução deste estudo, ao comparar-se dados estatísticos (anteriores a este estudo) da população carcerária, do sexo masculino, na pesquisa de ROZMAN et al. (1996, MASSAD et al, 1999) em que o padrão encontrado na Instituição Penitenciária, Casa de Detenção de São Paulo, conhecida como CARANDIRÚ, mostra a tendência de aumento da soropositividade para anti-HIV (16\%) e anti-HCV (34\%).

No sexo feminino, destaca-se a evolução citada, na população do estudo de FERREIRA (1997), na Penitenciária Feminina do Estado de São Paulo, onde é afirmado que o risco mais frequente são as drogas injetáveis, ou seja, 45,2\% do total da população, no momento da pesquisa detidas assumiram fazer uso de drogas ilícitas, sendo que destas, $24,1 \%$ usavam drogas injetáveis.

Encontrou-se na literatura, no sexo masculino, o estudo de 1987, com 923 prisoneiros do Sistema Penitenciário do Estado de São Paulo(PEIXINHO et al., 1990) com uma soroprevalência para a AIDS de 12,5\% e LORENÇO (1992), outro estudo do Sistema Penitenciário de São Paulo, no sexo masculino, uma soroprevalência para o anti-HIV de 14,9\% em 1990 e 17,3\% em 1991.

Demonstra-se, claramente, a dupla transmissão que estas populacões estão expostas ao vírus HIV, não somente pela atividade sexual insegura, mas também pela injeção de drogas, demonstrado no estudo de ROZMAN et al. (1996) que apresenta o HCV (vírus da Hepatite C) como marcador para a transmissão parenteral do HIV.

O número de trabalhos brasileiros que demonstram a alta prevalência do HIV entre os IDUs (usuários de drogas injetáveis) é bem conhecido na casuística brasileira (CARVALHO et al, 1996; CARVALHO, 1995; SEIBEL et al, 1998; BARATA et al., 1993; MESQUITA et al., 1992; MASSAD et al, 1994; MASSAD et al., 1999).

Embora, os UDIs (usuários de drogas injetáveis) sejam, realmente, um grupo que mereça a atenção especial da Saúde pública pelo próprio comportamento inadequado da lavagem de seringas, que faz com que sejam portadores de infecções de transmissão parenteral não só individualmente, como também na transmissão para a comunidade em que estão inseridos (DES JARLAIS e FRIEDAM, 1994; DES JARLAIS e FRIEDAM, 1993), destacam-se afimações deVARELLA (1999), quanto 
à uma nova frente diante do crack na Casa de Detenção do CARANDIRÚ, que em sua opinião

“ transtornou a cadeia... a estrutura do poder interno, a moral da malandragem e gerou mais violência...é droga traiçoeira... a pedra acaba com a vergonha na cara do cidadão".

NAPPO et al. (1994) afirmam que o crack leva o indivíduo ao isolamento social, a descuidar-se do próprio corpo, interromper com seus relacionamentos afetivos, à paranóia e praticar os atos anti-sociais que o conduz à marginalização. Traça, também, um perfil dos usuários de crack que faz lembrar das histórias de vida semelhantes da população da amostra deste estudo, ou seja, FEBEM MASCULINA E FEMININA, com marcos sócios-culturais e ambientes preferenciais (bares, ruas...) que torna,mais compreensível o porquê destes(as) meninos(as) encontrarem-se detidos por seus atos infracionários.

Nesta pesquisa de NAPPO et al. (1994), predominantemente de jovens, a maior parte de sua amostra $(56 \%)$ encontrava-se no $1^{\circ}$ grau, sendo que $76 \%$ dos entrevistados declarou não estar trabalhando. Salienta-se o baixo desempenho escolar, que o crack conduz o indivíduo e dificulta atividades que exijam atenção e responsabilidade, conduzindo o usuário, em pouco tempo, ao abandono de seus afazeres pessoais e sociais. Os depoimentos deixam transparecer o desafio que, esta droga, produz ao citar a sensação de bem estar, ilusão de onipotência, forte autoconfiança...efeitos que permanecem com o indivíduo, no máximo, por quinze minutos, mas estes jovens, relatam a "fissura" (necessidade incontrolável da droga) e a paranóia ( sensação persecutória de estar sendo procurado pela polícia ou alguém, que pode ser da família), como outras sensações desagradáveis, após momentos de euforia produzidos pela droga.

Nos depoimentos (expontâneos) fica claro a necessidade, constante do uso da droga: "Não tinha como não usar, a gente fica careta, não entende o papo que rola" (NAPPO et al.,1994)

A pedra de crack não é uma via direta, como o sangue e o sexo, na transmissão do vírus HIV, porém NAPPO et al. (1994) esclarecem como o uso da mesma é continuidade do uso de drogas ilícitas, ou seja, complementação das mesmas. 
Urge lembrar, que para se obter o crack é necessário ter um poder aquisitivo e que num ambiente de confinamento, cadeia ou reformatório, a moeda que se faz presente é o cigarro e a prostituição do próprio corpo (VARELLA, 1999; MASSAD e STRAZZA, 1997).

Voltando aos UDIs, que segundo MESQUITA (1992), devem ser enfrentados como problema de Saúde Pública num primeiro passo, não deve ser esquecido o nível macro, pois a droga movimenta recursos de grande volume, perdendo, apenas, para o petróleo e armamentos; ela emprega milhares de desempregados através do tráfico. Atrás desse tráfico MESQUITA (1992) afirma que "vemos o envolvimento de várias autoridades formais: presidentes, ministros, juizes, deputados, prefeitos...combater a droga, portanto, significa se defrontar com poderosos interesses políticos e econômicos, além da implicação social do problema. Não é à toa que a "guerra contra as drogas"é um fracasso absoluto".

A tragédia de Gaetan Dugas reflete, infelizmente ainda, a desinformação somada a irresponsabilidade, arrogância e desespêro de pessoas contagiadas pelo vírus HIV.

Houve neste período, sem dúvida, a conquista da liberdade individual, porém é importante registrar que ela deve ser acompanhada de limitações e precauções ao transformar-se em questão de Saúde Pública, que faz com que a AIDS seja, no momento inquestionavelmente, o seu maior desafio.

A Saúde Pública tem absorvido o impacto causado pelo vírus HIV no âmbito social. Porém, ao se recordar como foi gerado este impacto, imediatamente a mídia se faz presente com as primeiras notícias de jornais e televisão sobre AIDS que diziam:

- “SE VOCÊ NÃO CORRER O BICHO TE PEGA”;

-“A AIDS MATA...”

A ignorância e a notícia espalhafatosa fizeram com que as pessoas ficassem paralizadas pelo mêdo (SILVEIRA, 1990), frente a uma doença incurável e não buscassem não só a informação correta, mas os meios de se viver, com maior qualidade de vida, sendo portador deste vírus. 
Aqui poderia formular-se uma pergunta: Por que a AIDS?

Outros fenômenos sociais estão ocorrendo, tais como: a fome, guerras, terrorismo, violência urbana...

Uma possível resposta encontrar-se-ia no fato da AIDS ter sido gerada com o horror da morte, porém é fundamental recordar-se que está instaurado com a AIDS o grande paradoxo da modernidade, ou seja, ela conduz a morte ambos os genêros: masculino e feminino; some-se a isso que devem se contaminar com os símbolos da vida: sangue e sexo!

Talvez a AIDS continue sendo um dos grandes desafios para o primeiro século do próximo milênio, capaz de mobilizar o mundo científico e as relações humanas em muitas direções, técnicas e humanísticas.

Os resultados aqui apresentados levantam muitas preocupações sobre o futuro de adolescentes infratores detidos em reformatórios. A prevalência de doenças graves como a AIDS e a hepatite C, já elevadas no momento em que este trabalho foi realizado, tendem a aumentar visto que os comportamentos e hábitos destes adolescentes não estão de acordo com a consciência dos riscos oriundos de suas práticas sexuais e uso de drogas, fazendo deles um grupo vulnerável apesar do conhecimento a respeito da transmissão do vírus da AIDS.

Com esta afirmação e com o diagnóstico da FEBEM exposto neste trabalho, fica difícil imaginar a oportunidade e o destino de reintegração à sociedade dos menores infratores. 


\section{CONCLUSÕES}

A soroprevalência para o HIV entre adolescentes infratores detidos na Fundação do Bem-estar do Menor de São Paulo apresenta diferença estatisticamente significativa entre o gênero feminino $(10,3 \%)$ e o masculino $(2,6 \%)$.

No caso do vírus da hepatite $\mathrm{C}$, não há diferença da soropositividade entre os gêneros, sendo $4,6 \%$ e 5,9\% respectivamente para o grupo feminino e masculino estudado, ambos com prevalência acima da população geral.

Quanto a escolaridade, não foi observada diferença de gênero, sendo que mais de $90 \%$ não completou o ciclo fundamental, e 3\% são analfabetos.

Mais de $90 \%$ da população de adolescentes infratores estudada tem vida sexual ativa, não havendo diferença entre o sexo feminino e masculino.

Dentre os comportamentos sexuais foi possível detectar diferenças significativas entre gêneros quanto ao número de parceiros sexuais, sexo anal, sexo comercial, comportamento homo e bissexual, parceiro sexual de risco e ocorrência de doença sexualmente transmissível.

O uso de camisinha é pouco frequente para ambos gêneros, estando em torno de $20 \%$ o uso referido em todas as relações sexuais.

O abuso de álcool (68\%) e drogas ilícitas como a maconha (84\%), a cocaína (63\%) e crack (56\%) é semelhante para ambos gêneros.

Entre as adolescentes femininas, ocorreu pelo menos uma gravidez em $42 \%$ do grupo estudado, sendo que dentre estas jovens $70 \%$ fez pelo menos um aborto.

A população estudada mostrou bom nível de conhecimento sobre comportamentos de risco relacionados com a transmissão do HIV: $95 \%$ sabiam que a prática sexual sem camisinha e a exposição ao sangue podem transmitir o vírus da AIDS. Mais de $80 \%$ destes adolescentes afirmaram que uma pessoa aparentemente saudável pode ser portadora do HIV e transmití-lo. 
A via de transmissão sexual do HIV parece ser o principal fator de vulnerabilidade entre as adolescentes do sexo feminino, com o odds ratio de 8,13 para a prática de sexo comercial.

Por outro lado, a via parenteral está fortemente indicada como fator de vulnerabilidade para a transmissão do HIV entre os adolescentes do sexo masculino, com odds ratio de 20,77 para o uso de drogas injetáveis, 6,67 para a prática de compartilhamento de seringas entre usuários de drogas injetáveis e 4,60 para o uso de cocaína.

Finalmente, conclui-se que há uma clara contradição entre o conhecimento destes adolescentes sobre a transmissão do HIV e seus comportamentos tanto sexuais quanto práticas de uso de drogas, colocando-os como um grupo de elevada prevalência de AIDS, entre outras doenças graves. 


\section{REFERÊNCIAS BIBLIOGRÁFICAS}

ABERASTURY, A. e KNOBEL, M.- Adolescência Normal Artes Médicas, Porto Alegre, 8 edição, 1981.

ALMEIDA, M.A.V. Instrução Programada - Teoria e Prática Fundação Getúlio Vargas, Rio de Janeiro, II Série, 1970.

AUGUSTO A. As Duas Faces da FEBEM, Jornal da Tarde, São Paulo, 21 de julho de 1996, página 6 D. in FERREIRA D.P.; Desenvolvimento de um Sistema de Informações, em Intranet, para uma Organização Responsável pelo Atendimento ao Adolescente em Conflito com a Lei (FEBEM-SP), (tese de doutorado) Departamento de Patologia da Universidade de São Paulo, 1999.

AYRES J.R. Vulnerabilidade dos jovens ao HIV/AIDS. In A escola e a construção de uma resposta social, Silva L.H., editora Vozes, Petropólis, 1 edição, 1998.

AYRES J.R. O Jovem que buscamos e o encontro que queremos ser - A Vulnerabilidade como eixo de avaliação de ações preventivas do abuso de drogas, DST e AIDS entre crianças e adolescentes. In Papel da educação na ação preventiva ao abuso de drogas e às DSTs/AIDS, Fundação para o desenvolvimento da educação-FDE- diretoria de projetos especiais/diretoria técnica- série Idéias, 29, São Paulo, 1996

BARATA L.C.B., ANDRIGUETTI M.T.M., MATOS M.R.; Surto de Malária Induzida em Usuários de Drogas Injetáveis, Revista Saúde Pública, v. 27, n.1 p. 914, 1993.

BASTOS C.,GALVÃO J.,PEDROSA J.S., PARKER R. in AIDS NO BRASIL PARKER R., BASTOS C.,GALVÃO J.,PEDROSA J.S., editora Abia Relume, IMS-UERJ Dumará, 1 ediçãp, 1994.

BOLETIM EPIDEMIOLÓGICO, ano XVII, número 1, Programa DST AIDS, Secretaria de Estado da Saúde de São Paulo, julho de 1999. páginas 18 a 21.

BOWLBY J.; A Tendência Anti Social in Da Pediatria à Psicanálise, D. W. Winnicott, livraria Francisco Alves, editora S.A., Rio de Janeiro, 2 edição, 1982.

BOOTH R.E., ZHANG Y.,M. - Severe Agression and Related Conduct Problems Among Runaway and Homeless Adolescents - Psychiatric Services, Vol. 47, n. 1, pp. 75-80, 1996.

BUCHALLA C. - Apostila do Curso de Epidemiologia do HIV e da AIDS: HEP-928; Faculdade de Saúde Pública, Departamento de Epidemiologia, 4 à 26 de agosto de 1993.

BURATTINI, M.N.; ZANETTA, D.M.; AZEVEDO, R.S.; BUCHALLA, C.; STRAZZA, L.; MASSAD, E.; TAKEI, K.; YAMAMOTO, Y. - Demographic 
Aspects And Risky Behaviors Among University Students Of São Paulo, Brazil. Abstract Book Of 12 ${ }^{\text {th }}$ World Aids Conference Geneva, Abs 14.325, Pg 247, 1998.

CAMPOS M.; FEBEM nega denúncias, Jornal da Tarde, SãoPaulo, 19 de fevereiro de 1998, página 9.A. in FERREIRA D.P.; Desenvolvimento de um Sistema de Informações, em Intranet, para uma Organização Responsável pelo Atendimento ao Adolescente em Conflito com a Lei (FEBEM-SP), (tese de doutorado) Departamento de Patologia da Universidade de São Paulo, 1999.

CARVALHO H.B.; Dinâmica de Transmissão do HIV Entre Usuários de Drogas Injetáveis na Cidade de Santos, São Paulo, Brasil, 156 p., (Tese de doutorado) Faculdade de Medicina da Universidade de São Paulo, Departamento de Patologia, 1995.

CARVALHO H.B.; MESQUITA F., MASSAD E.,BUENO R., LOPES G.T., RUIZ M.A., BURATTINI M.N.; HIV and infection of Similar Transmission Patterns in Drug Injectors Community of Santos, Brasil, Journal of Acquired Immune Deficiency Sindromes and Human Retrovirology n.2, p.84-92, 1996.

CARVALHO H.B.; BURATTINI M.N., MASSAD E., MESQUITA F., BUENO R.C., LOPES G.T. \& RUIZ M.A.; Prevalence of HIV among IDUs in SantosBrazil: analysis of HIV risk factors and gender differences in behavior. Abstract book, XI International Conference on AIDS 2:454, abs Pub.C.1009,1996.

CATANIA J.A., KEGELES S.M., COATES T.K., Towards an Understanding of Risk Behavior: an AIDS Risk Reduction Model (ARRM). Health Education Quartely 17(1):53-72, 1990.

CANTERBURY R.J., MCGARVEY E.L., SHELDONKELLER A.E., WAITE D., REAMS P., KOOPMAN C. - Prevalence of HIV Related Risk Behaviors and STDs Among Incarcerated Adolescents - Journal of Adolescent Health, Vol. 17, N. 3, pp. 173-177, 1995.

CFP resolução número 01/99 in Jornal do CRP São Paulo; ano 17, edição especial, número 115/116, março/junho de 1999.

COSTA J.F.; A Ética e o Espelho da Cultura, Editora Rocco, Rio de Janeiro, 1 edição 1994.

CORNEAU G. Pai Ausente Filho Carente, editora brasiliense, São Paulo, 1 edição, 1991.

CRITICAS À FEBEM; Jornal da Tarde, São Paulo,11 de outubro de 1996, página 10 A. in FERREIRA D.P.; Desenvolvimento de um Sistema de Informações, em Intranet, para uma Organização Responsável pelo Atendimento ao Adolescente em Conflito com a Lei (FEBEM-SP), (tese de doutorado) Departamento de Patologia da Universidade de São Paulo, 1999.

DAVID H.; JOSEPH B.; ROSENFELD S. D.-Reviews of Infections Diseases, 9 (6): 1102-1108, 1987. 
DE PALMA M.T.; MCCALL M.; English G.; Increasing Perceptions Of Disease Vulnerability Through Imagery, Journal Am Coll Health, march, 44:5, 226-34, United States, 1996.

DEISHER R.W.,ROGERS W.M.;The Medical Care of Street Youth, Journal of Adolescents Health, Vol.12, N. 7,pp. 500-503, 1991.

DES JARLAIS D.C., FRIEDMAN S.R., AIDS and the Use of Injected Drugs, Sci Am, v.270, n.2 p. 56-62, 1994

DES JARLAIS D.C., FRIEDMAN S.R., Critical Issues Regarding AIDS Among Injecting Drugs Users, The Global difusion of Injecting Drug User: implications for Human immunodeficiency virus infection. Bull Narc, v.45,n.1,p.61-75, 1993.

DE GREEFF in Ensaio de Psicologia Criminal, Dourado L.A., Zahar editores, $1^{\text {a }}$ edição, Rio de Janeiro ,1969.

DIXON P.S., FLANIGAN T.P., DE BUONO B.A, LAURIE J.J., DE CIANTS M.L., HOY J., STEIN M., SCOTT H. DENMAN, CARPNTER C.C.J. Infection with the Human Immunodeficiency Virus in Prisoners: Meeting the Health Care Challenge, The American Journal of Medicine, 95:629-35, 1993.

DOURADO L.A., Ensaio de Psicologia Criminal, Zahar editores, Rio de Janeiro , $1^{\text {a }}$ edição, 1969.

DRYFOOS 1990 In Violência na vida dos Adolescenes, Straus M.B., editora Best Seller, São Paulo, 1 edição, 1994.

ECKERSLEY R.; Failing a Generation - The Impact of Culture on the Health and Well Being of Youth, Journal of Pediatrics and Child Health, 29(S1):S6-19, 1993.

EISENSTEIN E.; Street Youth Social Imbalance and Health Risks, Journal of Paediatrics and Child Health, 29(S1):S46-9, 1993.

ENGLISH A., Runaway and Street Youth at Risk for HIV Infection- Legal and Ethical Issues in Access to care, Journal of Adolescent Health, Vol. 12, N. 7, pp. 504-510, 1991.

ESTUDO liga menor inflator às drogas, Jornal da Tarde, São Paulo, 10 de março de 1998, página 12 A in FERREIRA D.P.; Desenvolvimento de um Sistema de Informações, em Intranet, para uma Organização Responsável pelo Atendimento ao Adolescente em Conflito com a Lei (FEBEM-SP), (tese de doutorado) Departamento de Patologia da Universidade de São Paulo, 1999.

EVANS A.S.; Viral Infections of Humans - Epidemiology and Control, Plenum Medical Book Company, New York and London, 3 edição, 1989.

EVELYN A.C., FINE P.M.;Effects of AIDS, Cocaine and Family Violence On Children In Out of Home Care, Journal Nebr. Med., 77:9, 245-52,September, 1992. 
FARROW J.A., DEISHER R.W., BROW R.; Proceedings of the West Coast Scientific Symposium on Health Care of Runaway and Street youth-introduction, Journal of Adolescent Health, Vol. 7, pp.497-499, 1991.

FEITEL B., MARGETSON N., CHAMAS J., LIPMAN C.; Psychosocial Background and Behavioral and Emotional Disorders of homeless and runaway youth, Hospital and Community Psychiatry, Vol. 43, N. 2, pp. 155-159, 1992.

FERNANDES J.C.; Trends in HIV/AIDS-related knowledge, attitudes, and practices in a Rio de Janeiro slum population, Caderno de Saúde Pública, Julho, 14:3, 57581, 1998.

FERREIRA A.B.H.; Novo Dicionário da Língua Portuguesa, editora Nova Fronteira, Rio de Janeiro, 1 edição.

FERREIRA D.P.; Desenvolvimento de um Sistema de Informações, em Intranet, para uma Organização Responsável pelo Atendimento ao Adolescente em Conflito com a Lei (FEBEM-SP), (tese de doutorado) Departamento de Patologia Faculdade de Medicina da Universidade de São Paulo, 1999.

FERREIRA M. M. C.;Infecção Pelos Retrovírus HIV-1, HTLV-I E HTLVII Na População Feminina Da Penitenciária do Estado de São Paulo-Prevalência, Fatores de Risco E Conhecimento Desse Risco (tese de doutorado), Departamento de Epidemiologia da Faculdade de Saúde Pública da Universidade de São Paulo, 1997.

FRANK D.A. e ZEIZEL S.H.; Deficiência de Desenvolvimento-in Crianças em Risco:questões médicas e sociais atuais, Clínicas Pediátricas da América do Norte, Volume 6, Interlivros editores Ltda, Rio de Janeiro-1 edição, 1998.

FREIRE P.; A Educação na Cidade, editora cortez, São Paulo, 1 edição, 1991.

FREIRE P.; Pedagogia do Oprimido, editora paz e terra, Rio de Janeiro, 7 edição, 1979.

FREUD, A.; Adolescence - the psychoanalytic study of the child. New York, International University Press, XIII, 1958

FREUD, S.; Luto e Melancolia in Obras Completas -, Vol.XIV, editora Imago, Rio de Janeiro, 1 edição, 1974.

FRIGINI R. - Pequenas Causas, Livraria e Editora de Direito Ltda, Leme, $1^{\text {a }}$ edição,1995.

FUNDAÇÃO ESTADUAL DO BEM ESTAR DO MENOR; Assessoria de Planejamento, Planejamento para 1996, São Paulo, FEBEM/SP, 1996 in FERREIRA D.P.; Desenvolvimento de um Sistema de Informações, em Intranet, para uma Organização Responsável pelo Atendimento ao Adolescente em Conflito com a Lei (FEBEM-SP), (tese de doutorado) Departamento de Patologia da Universidade de São Paulo, 1999. 
FUNDAÇÃO ESTADUAL DO BEM ESTAR DO MENOR; Assessoria de Planejamento, Dados Gerais da FEBEM/SP, agosto de 1998, São Paulo, FEBEM/SP in FERREIRA D.P.; Desenvolvimento de um Sistema de Informações, em Intranet, para uma Organização Responsável pelo Atendimento ao Adolescente em Conflito com a Lei (FEBEM-SP), (tese de doutorado) Departamento de Patologia da Universidade de São Paulo, 1999.

FUNDAÇÃO ESTADUAL DO BEM ESTAR DO MENOR; Assessoria de Planejamento,Relatório de Gestão,1995/1998, São Paulo, FEBEM/SP in FERREIRA D.P.; Desenvolvimento de um Sistema de Informações, em Intranet, para uma Organização Responsável pelo Atendimento ao Adolescente em Conflito com a Lei (FEBEM-SP), (tese de doutorado) Departamento de Patologia da Universidade de São Paulo, 1999.

FUNDAÇÃO ESTADUAL DO BEM ESTAR DO MENOR; Assessoria de PlanejamentoRelatório de Informações Gerenciais, abril de 1998, São Paulo, FEBEM/SP in FERREIRA D.P.; Desenvolvimento de um Sistema de Informações, em Intranet, para uma Organização Responsável pelo Atendimento ao Adolescente em Conflito com a Lei (FEBEM-SP), (tese de doutorado) Departamento de Patologia da Universidade de São Paulo, 1999.

GRINBERG L.; El individuo frente a su identidad, Buenos Aires, Revista de Psicoanálisis, XVIII, pág. 344, 1961.

GRUNBAUM J.A.;BASEN-ENGQUIST K.; PANDEY D.; Association Between Violent Behaviors and Substance Use Among Mexican-American and NonHispanic White High School Students, Journal Adolescent Health, v.23, p153-9, 1998 in FERREIRA D.P.; Desenvolvimento de um Sistema de Informações, em Intranet, para uma Organização Responsável pelo Atendimento ao Adolescente em Conflito com a Lei (FEBEM-SP), (tese de doutorado) Departamento de Patologia da Universidade de São Paulo, 1999.

HOPCKE R.H.; Jung, Jungianos e a Homossexualidad, editora Siciliano, São Paulo, 2 edição, 1993.

HOWARD J.; Talking a Chance on Love, Risk Behavior of Sidney Street Youth, Journal of Paeditrics and Child Health, Vol. 29, N. S. 1, pp. S. 60-S 65, 1993.

JUNG C.G.; O Eu E O Inconsciente, editora Vozes, Petrópolis, 3 edição, 1982.

KAY H., DODD B. e SIME M.; Iniciação à Instrução Programada e às Máquinas de Ensinar, Ibrasa S.A., São Paulo, 1970.

KIPLE M.D., OCONNOR S., PALMER R., MACKENZIE R.G.; Street Youth in Los Angeles, Profile of a Group at High-Risk for Human Immunodeficiency Virus Infection , Archives of Pediatrics \& Adolescent Medicine, 1995, Vol. 149, N. 5, pp. 513-519. 
KLEIN M., ISAACS S., SHARPE E. F., SEARL N., MIDDLEMORE M.; - A Educação de Crianças - À luz da investigação psicanalítica, Editora Imago, Rio de Janeiro, 2 edição, 1973.

KLEIN M.; Amor, Ódio e Reparação, Editora Imago no Rio de Janeiro e Editora da Universidade São Paulo em São Paulo, , 2 edição, 1975.

KOSA F, LASZIK A., ANTAL A, SZENDRENYI J.; Juvenile Delinquency and Drug Dependence in Hungary, Forensic Science International, Vol. 62, N. 1-2, pp. 2936, 1993.

JORNAL DO CRP SÃO PAULO; Ano 17, edição especial, número 115/116, março/junho de 1999.

LAPLANCHE J. e PONTALIS J.B.; Vocabulaire de la psychanalyse, Presses Universitaires de France, Paris, p. $184,1967$.

LORENÇO R. Epidemiologia da Infecçao pelo HIV-1 nas Instituições Carcerárias Brasileiras Masculinas do Complexo Penitenciário do Carandirú, Tese de Mestrado, Escola Paulista de Medicina, São Paulo, Brasil, 1992.

LOZANO A.; Estudo derruba mitos sobre menor de rua, Folhade São Paulo, São Paulo, 19 de outubro de 1997, página3-1 in FERREIRA D.P.; Desenvolvimento de um Sistema de Informações, em Intranet, para uma Organização Responsável pelo Atendimento ao Adolescente em Conflito com a Lei (FEBEM-SP), (tese de doutorado) Departamento de Patologia da Universidade de São Paulo, 1999.

LUIZ E.; Ministro defende redução da maioridade pena, Jornal da Tarde, São Paulo, 20 de fevereiro de 1988, página 20 in FERREIRA D.P.; Desenvolvimento de um Sistema de Informações, em Intranet, para uma Organização Responsável pelo Atendimento ao Adolescente em Conflito com a Lei (FEBEM-SP), (tese de doutorado) Departamento de Patologia da Universidade de São Paulo, 1999.

MASSAD E., COUTINHO F.A.B., YANG H.M., CARVALHO H.B., MESQUITA F.\& BURATTINI M.N.,The Basic Reproduction Ratio of HIV among Intravenous Drug Users, Mathematical Biosciences 123: 227-247, 1994.

MASSAD E., BURATTINI M.N., AZEVEDO-NETO R.S., STRAZZA L., MENEZES R.X., CARVALHO H.B., MEDEIROS M., PETRESCU C.S., ALMEIDA L.N.B., CASTRIGNANO S.B., MENEGHIM P. \& NEITZERT E.; The Prevalence of HIV and Risk-taking behavior among disadvantaged youth in São Paulo-Brazil. Abstract book, XI International Conference on AIDS 2:461, abs Pub.C.1146, 1996.

MASSAD E.;STRAZZA L., - DADOS ESTATÍSTICOS DA FEBEM, E aí camarada?(cartilha), NUPAIDS-USP, 1997.

MASSAD E., ROZMAN M.;. AZEVEDO R.S.; SILVEIRA A.S.B.; TAKEY K.; YAMAMOTO Y.I.; STRAZZA L.; FERREIRA M.M.C. ; CARVALHO H.B.\& 
BURATTINI M.N. - Seroprevalence of HIV, HCV and Syphilis in a Brazilian Prisoners. European Journal of Epidemiology, 15(5): 439-445. 1999.

MARTINS T., O. O Menor Infrator: Aspectos Teóricos e Práticos in Adolescência: entre o passado e o futuro, AssociaçãoPsicanalítica de Porto Alegre, Artes e Ofícios Editora LTDA.,Porto Alegre, 1 edição,1997.

MARTIN V., GONZALEZ P.,CAYLÁ J.A., MIRABENT J., CAÑELLAS J., PINA J.M.\& MIRET P.; Case Finding of Pulmonary Tuberculosis on Admission to a Penitentiary Centre, Tubercle and Lung Disease 75 (1):49-53, 1994.

MESQUITA F.; Drogas injetáveis e AIDS in Paiva V.,Em Tempos de Aids, Summus editora, São Paulo, 1 edição,1992.

MINISTÉRIO DA SAÚDE, www.aids.gov.br , 28 de julho de 1999

MOORE S, ROSENTHAL D., The Social Context of Adolescent Sexuality: safe Sex implications, Journal Adolescent, december,15:4, 415-35,England, 1992.

MORRIS R.E., HARRISON E.A., KNOX G.W., TROMANHAUSER E., MARQUIS D.K., WATTS L.L.; Health Risk Behavioral Survey From 39 Juvenile Correctional Facilities in the United States, Journal of Adolescent Health, , Vol.17, N.6, pp.334344, 1995.

NAPPO S.A., GALDUROZ J.C.F., NOTO A.R.; Uso do Crack em São Paulo: fenômeno emergente? Revista ABP-APAL 16(2): 75-83, 1994.

OMS; Classificação Internacional de Doenças, Artes Médicas, Porto Alegre, 10 revisão, 1993.

OLIVEN R.G.; Violência e Cultura no Brasil, Editora Vozes, Petropólis, 1983.

PAIVA V.;Em Tempos de Aids, Summus editorial, São Paulo, 1 edição, 1992.

PANTALEO G.,GRAZIOSI C. \& FAUCI A.S.;The Immunopathogenesis of Human Immunodeficiency Virus Infection, The New England Journal of Medicine, vol 328 (3): 327-335, 1993.

PARKER R.; BASTOS C., GALVÃO J. e Pedrosa J.S.; A AIDS no Brasil, Abia Relume e IMS, UERJ Dumará, Rio de Janeiro, 1994.

PARKER R. e DANIEL H.; - AIDS- A Terceira Epidemia - dois olhares se cruzam numa noite suja, editora Iglu,São Paulo, 1edição, 1991.

PASTORE D.R.; FISHER M.; FRIEDMAN S.B.; Violence and Mental Health Problems Among Urban High School Students, Journal Adolescent Health, V.18, p.320-4, 1996 in FERREIRA D.P.; Desenvolvimento de um Sistema de Informações, em Intrenet, para uma Organização Responsável pelo Atendimento ao Adolescente em Conflito com a Lei (FEBEM-SP), (tese de doutorado) Departamento de Patologia da Universidade de São Paulo, 1999. 
PEIXINHO Z.F.e MENDES N.F.; Seroepidemiological Studies of HIV-1 Infection in Large Brazilian Cities, Natural Immunity and Cell Growth Regulation 9:133-136, 1990.

PERSSON E. and JARLBRO G.; Sexual behavior Among Youth Clinic Visitors in Sweden Knowledege and experiences in an HIV Perspective, Genitourinnary Medicine, Vol.68, N.1, pp 26-31, 1992.

PELlEGRINO H.; Pacto Edípico e Pacto Social, Folha de São Paulo, Caderno Folhetim,11 de setembro de 1983.

POVINELLI M.,REMAFEDI G.,TAO GY.,1996 - Archives Of Pediatrics \& Adolescents Medicine, 1996, vol.150,n.1,pp.33-38.

REICH W.; Psicologia de Massas do Fascismo, editora Martins Fontes, São Paulo, 2 edição, 1988.

RESNICK M.D., HARRIS L.J., BLUM R.W.; The Impact of Caring Connectedness on Adolescent Health and Well-Being, Journal of Paeditrics and Child Health, Vol. 29, N. S 1, pp. S 3 - S 9, 1993.

REULER J.B.; Outreach Health Services for Street Youth, Journal of Adolescents Health, Vol.12, N.7, pp. 561-565, 1991

ROZMAN M., MASSAD E., BURATTINI M.N., SILVEIRA A.S.B., AZEVEDONETO R.S., TAKEY K., YAMAMOTO Y.I., STRAZZA L., MENEGHIN P., FERREIRA M.M.C., CARVALHO H.B., BUCHALA C.M.,\&SCHECHTMAN M., Transmission of HIV/AIDS in a Major Brazilian Prison: relationship with time of imprisonment. abstract book of the 7 International Congress for Infectious Diseases, pg.12, abs 11007, 1996.

ROTILY M., PUJOL A.G., OBADIA Y., MOATTI J.P., TOUBIANA P., VAIASSE C. V., GASTAUT J.A.; HIV Testing, HIV Infection and Associated Risk Factors Among Inmates in S outh- Eastern French Prisons, AIDS, 8:1341-1344, 1994.

SANER H.; ELLICKSON P.; Concurrent Risk Factors for Adolescent Violence, Journal Adolescente Health, V.19, p.94-103, 1996 in FERREIRA D.P.; Desenvolvimento de um Sistema de Informações, em Intranet, para uma Organização Responsável pelo Atendimento ao Adolescente em Conflito com a Lei (FEBEM-SP), (tese de doutorado) Departamento de Patologia da Universidade de São Paulo, 1999.

SCHRAM DD. e GIOVENGO M.A.; Evaluation of Threshold in Independent Living Program for Homeless Adolescents, Journal of Adolescent Health, Vol.12, N. 7, pp. 567-572. 1991..

SCHERER S.; Dominação Ideológica Versus Lazer Psicotrópico in Drogas Hegemonia do Cinismo, Seibel S.D. e Ribeiro MM., Fundaçao Memorial da América Latina, São Paulo, 1 edição, 1997. 
SEIBEL S.D.,CARVALHO H.B., SANTOS V.A., REALE D., MASSAD E.; Padrões de morbidade e comportamentais associados à violência entre usuários de drogas ilegais, com ênfase no crack, em indivíduos em tratamento em instituição pública na cidade de São Paulo, Cidadania e direito à saúde mental, Collectanea Symposium, Série Medicina\&Saúde, Frontis Editorial, São Paulo, 1 edição, 1998

SCHRAM DD. e GIOVENGO M.A.; Evaluation of Threshold in Independent Living Program for Homeless Adolescents, Journal of Adolescent Health, Vol.12, N. 7, pp. 567-572. 1991..

SIBTHORPE B., DRINKWATER J., GARDNER K., BAMER G.; - Drug Use, Binge Drinking and Attempted Suicide among Homeless and Potentially Homeless Youth - Australian and New Zealand, Journal of Psychiatry, Vol. 29, N. 2, pp.248-256, 1995.

SILVEIRA N.; Jung - vida e obra, editora Paz e Terra,Rio de Janeiro, 1990, 12 edição.

SKINNER B.F.; Tecnologia do Ensino. E.P.U. e EDUSP, São Paulo, Segunda Edição, 1972.

SOUZA L.; Linchamentos, Contribuições e Limitações da Análise de Comportamento da B.F. Skinner, PUC-SP-1986.

SOUZA P.; Desembargador visita a FEBEM e sai indignado, Jornal da Tarde, São Paulo, 23 de setembro de 1996, página 11A.in FERREIRA D.P.; Desenvolvimento de um Sistema de Informações, em Intranet, para uma Organização Responsável pelo Atendimento ao Adolescente em Conflito com a Lei (FEBEM-SP), (tese de doutorado) Departamento de Patologia da Universidade de São Paulo, 1999.

STANTON B.F., LI X., GALBRAITH J., FEIGELMAN S., KALJEE L.; Sexually Transmitted Diseases, Human Immunodeficiency Virus and Pregnancy Prevention Combined Contraceptive Practices Among Urban African American Early Adolescents , Archives of Pediatrics \& Adolescent Medicine, V.150,n. 1, pp.17-24, 1996.

STRAUS M.B.; Violência na Vida dos Adolescentes, Editora Best Seller , São Paulo, 1 edição, 1994.

STRAZZA L., MASSAD E., BURATTINI M.N., ZANETTA D., CARVALHO H., AZEVEDO, R.S. - Std And Hiv Infection In Disadvantaged Female And Male Adolescents Of São Paulo, Brazil. Abstract Book Of $8^{\text {th }}$ International Congress On Infectious Diseases, Boston, MA, EUA, Abs 16.033, Pg 50, 1998.

STRAZZA L., MASSAD E., BURATTINI M.N., ZANETTA D., CARVALHO H., AZEVEDO, R.S. - A Vunerability Approach To Hiv / Aids Infection In Disadvantage Female Adolecents Of São Paulo, Brasil. Abstract Book Of $8^{\text {th }}$ International Conference On The Reduction Of Drug Related Harm, Paris, França, Pg 151, 1997. 
STRAZZA, L.; ZANETTA, D.M.T.; MASSAD, E.; CARVALHO, H.B.; AZEVEDO, R.S.; MENEZES, R.X.; BURATTINI, M.N. - Hiv Infection Among Disadvantaged Youth Of São Paulo, Brazil. Abstract Book Of 12th World Aids Conference Geneva, Genebra, Suíça, Abs 13.171, Pg 119, 1998.

TÓFOLI D.; Escolas admitem dificuldades na prevenção às drogas, Jornal da Tarde, São Paulo, 20 de maio de 19998, página 15A in FERREIRA D.P.; Desenvolvimento de um Sistema de Informações, em Intranet, para uma Organização Responsável pelo Atendimento ao Adolescente em Conflito com a Lei (FEBEM-SP), (tese de doutorado) Departamento de Patologia da Universidade de São Paulo, 1999.

WINNICOTT D.W.; O Brincar e a Realidade, Imago Editora LTDA, Rio de Janeiro,1 edição, 1975

WINNICOTT D. W. ; Da Pediatria à Psicanálise, Livraria Francisco Alves Editora S.A., Rio de Janeiro, 2 edição, 1982.

WINNICOTT D.W. ; Alguns Aspectos Psicológicos da Delinquência Juvenil, Privação e Deliquência, Editora Martins Fontes,São Paulo, 1 edição, 1995.

VARELLA D.; Estação Carandirú, Companhia das Letras, São Paulo, 2 edição, 1999.

VÁZQUEZ A. S.; Filosofia da Praxis, Editora Paz e Terra, Rio de Janeiro, 4 edição, 1990.

VLAHOV D. and BREWER F., Prevalence to Hiv-1 among entrants to US Corretional Facilities, JAMA 265: 1129-1132, 1991.

ZANETTA D.M.T, MASSAD E., BURATTINI M.N.; PAIVA V., BUCHALLA C.M., STRAZZA L., MENEGHIN P. - The Prevalence Of Risk-Taking Behaviors Among University Students In São Paulo, Brazil. Abstract Book Of Xi International Conference On Aids, Vancouver, Canadá, Abs Mo.D. 1.687, Pg 172, 1996.

ZANETTA D.M.T., STRAZZA L., MASSAD E., BURATTIONI M.N., CARVALHO H. \& AZEVEDO R.S. - The Prevalence Of Hiv, Hcv And RiskTaking Behaviors Among Disadvantaged Male Adolescents Of São Paulo, Brazil. Abstract Book Of $8^{\text {th }}$ International Conference On The Reduction Of Drug Related Harm, Paris, França, Pg 164, 1997.

ZANETTA D.M.T., STRAZZA L., AZEVEDO R.S., CARVALHO, H.B., MASSAD E., MENEZES R.X., FERREIRA D.P. and BURATTINI M.N. HIV infection and related risk behaviors in a disadvantage youth institution of São Paulo, Brazil. International Journal of STD and AIDS 10(2): 98-104. 1999. 